\title{
Osteopontin (OPN/SPP1) isoforms collectively enhance tumor cell invasion and dissemination in esophageal adenocarcinoma
} \author{
G. Beer ${ }^{1}$, Lin Lin ${ }^{1}$ \\ ${ }^{1}$ Section of Thoracic Surgery, Department of Surgery, University of Michigan, Ann Arbor, MI, USA \\ ${ }^{2}$ Department of Pathology, University of Michigan, Ann Arbor, MI, USA \\ ${ }^{3}$ Department of Internal Medicine, University of Michigan, Ann Arbor, MI, USA \\ Correspondence to: \\ Lin Lin, e-mail: linlin@umich.edu \\ David G. Beer, e-mail: dgbeer@umich.edu \\ Keywords: OPN/SPP1 isoforms, co-overexpression, collective function, esophageal adenocarcinoma \\ Received: March 11, $2015 \quad$ Accepted: May 14, $2015 \quad$ Published: June 01, 2015
}

Jules Lin ${ }^{1}$, Amy L. Myers ${ }^{1}$, Zhuwen Wang ${ }^{1}$, Derek J. Nancarrow ${ }^{1}$, Daysha Ferrer-Torres ${ }^{1}$, Amy Handlogten ${ }^{1}$, Kimmy Leverenz ${ }^{1}$, Julia Bao ${ }^{1}$, Dafydd G. Thomas ${ }^{2}$, Thomas D. Wang ${ }^{3}$, Mark B. Orringer ${ }^{1}$, Rishindra M. Reddy ${ }^{1}$, Andrew C. Chang ${ }^{1}$, David

\section{ABSTRACT}

Esophageal adenocarcinoma (EAC) is often diagnosed at an advanced stage, thus understanding the molecular basis for EAC invasion and metastasis is critical. Here we report that SPP1/OPN was highly overexpressed in primary EACs and intracellularly localized to tumor cells. We further demonstrate that all known OPN isoforms (OPNa, b, c, 4 and 5) were frequently co-overexpressed in primary EACs. Distinct pro-invasion and dissemination phenotypes of isoform-specific OPNb and OPNc stable transfectants were observed. Expression of OPNb significantly enhanced cell migration and adhesion to laminin. In contrast, OPNc cells showed significantly decreased cell migration yet increased cell detachment. Enhanced invasion, both in vitro and in vivo, was observed for OPNb- but not OPNc-expressing cells. Inhibition of RGD integrins, one family of OPN receptors, attenuated OPNb cell migration, abrogated OPNb cell adhesion and significantly reduced OPNb cell clonogenic survival but did not affect OPNc phenotypes, indicating that OPNb but not OPNc acts through integrin-dependent signaling. Differential expression of vimentin, E-cadherin and $\beta$-catenin in OPN stable cells may account for the variation in cell adhesion and detachment between these isoforms. We conclude that while all OPN isoforms are frequently co-overexpressed in primary EACs, isoforms OPNb and OPNc enhance invasion and dissemination through collective yet distinct mechanisms.

\section{INTRODUCTION}

The incidence of esophageal adenocarcinoma (EAC) has increased steadily in the past four decades in many western countries, including the United States, with an overall survival of only $10-19 \%$ at 5 years [1-5] [http://seer.cancer.gov/statfacts/html/esoph.html]. Chronic gastroesophageal reflux disease is a major risk factor for the development of Barrett's esophagus, which leads to the increased likelihood of transformation to esophageal adenocarcinoma $[6,7]$. Greater than $64 \%$ of patients with resectable EAC present with locally advanced EAC or regional nodal disease [8]. The majority of patients with resectable EAC (T2 or N1 disease or greater) are treated with neoadjuvant chemoradiation therapy followed by esophagectomy. However, at the time of resection, only $21-29 \%$ of patients show a complete response, and these complete responders have improved survival outcomes [8-10]. Overall, $80 \%$ of all cancer patients succumb to metastatic diseases $[11,12]$. Controlling disease progression at presentation and enhancing patient response to existing treatment regimens are crucial to improving overall patient outcomes.

Although still poorly understood, studies have suggested that the biological cascade of invasion and metastasis includes loss of cellular adhesion, increased 
motility and invasiveness, entry into and survival in the circulation (intravasation), exit from the circulation at a distant site (extravasation), and colonization in the new tissue [13-16]. Mutual regulatory interactions between tumor cells and their extracellular matrix (ECM) are known to influence cancer progression [17-19]. Epithelialmesenchymal transition (EMT) has been associated with the acquisition of motility and invasiveness and has also been reported to contribute to cancer metastasis and chemoresistance [20-24]. Osteopontin (OPN) is one of these invasion- and metastasis-associated genes [25-27].

OPN, a secreted phosphorylated extracellular matrix (ECM) protein, is encoded by the highly conserved gene SPP1. OPN acts through multiple adhesion receptor binding motifs, including thrombin-cleaved N-terminal integrin domains (RGD for $\alpha v \beta 1, \alpha v \beta 3, \alpha v \beta 5, \alpha 5 \beta 1$ and $\alpha 8 \beta 1$; SVVYGLR for $\alpha 4 \beta 1, \alpha 9 \beta 1$, and $\alpha 9 \beta 4$ ) and a C-terminal CD44v6 domain [28-34]. Both integrin and CD44 receptors are not only involved in cell adhesion and other similar signaling pathways but also interplay with each other leading to tumor progression and metastasis [35-38]. OPN has been reported to play important roles in a wide range of biological and pathological processes, including tissue remodeling, inflammation, angiogenesis, immunity, tumor development, invasion and metastasis $[33,39]$. OPN has been studied as a potential therapeutic target in the regulation of cancer metastasis [39-41]. Activation of a CD44-dependent OPN/Aurora-A/ERK1/2 pathway has been reported, and OPN-activated Aurora-A has been proposed as a potential therapeutic target in head and neck squamous cell carcinoma [42]. Moreover, expression of OPN at histologically-negative surgical margins has been associated with higher recurrence of oral squamous cell carcinomas and, therefore, may be useful as a prognostic marker of recurrence [43]. We and others have reported transcriptional overexpression of OPN/SPP1 in primary EAC using global gene expression profiling studies [44-50]. Different OPN isoforms have been identified and have been reported to be associated with other types of malignancy [51-54]. However, whether OPN isoforms are transcriptionally exclusive in individual EACs and what their individual pathological roles are in EAC invasion and metastasis have not been fully elucidated. We report in the present study that all five OPN isoforms are co-overexpressed in the majority of primary EACs and that individual OPN isoforms show distinct phenotypes, yet act collectively in tumor invasion and dissemination in EAC/OPN cell models.

\section{RESULTS}

\section{SPP1 is highly overexpressed in primary EACs}

Affymetrix expression arrays of 46 esophageal samples representing the progression from Barrett's metaplasia and dysplasia to EAC were analyzed
(GSE37200). The gene SPP1 (secreted phosphoprotein 1, encoding osteopontin, OPN) was found to be highly overexpressed in EAC as compared to Barrett's metaplasia and dysplasia samples (Figure 1A). OPN has been reported to be associated with tumor invasion and metastasis. We validated OPN/SPP1 overexpression in an independent cohort of 107 EAC samples using realtime RT-PCR (Figure S1) and found significantly higher expression of OPN/SPP1 in all stages of EAC compared with Barrett's metaplasia (BE) and dysplasia (Figure 1B; $p<0.01$ for stage I EAC and $p<0.0001$ for all other stages). We observed a trend towards increased OPN expression among advanced stage tumors, although this did not reach statistical significance (Figure 1B). Analysis of 73 EAC DNA copy number profiles (GSE36460) [55] showed that the SPP1 locus was not associated with any significant DNA copy number gain or gene amplification (Figure 1C). We confirmed the SNP results using genomic qPCR analysis in 86 pairs of matched tumor and normal esophageal samples that included the cohort of 73 EACs analyzed by SNP (Figure 1D). Thus overexpression of OPN appears to be due to transcriptional regulation. Treatment of SPP1 endogenous low-expressing Flo cells with 5-aza-2'-deoxycytidine (decitabine), an epigenetic modifier that inhibits DNA methyltransferase activity, resulted in detectable expression of the gene, whereas abundantly SPP1-expressing H460 cells were not affected by treatment (Figure 1E), suggesting that SPP1 expression could be epigenetically regulated, consistent with results recently reported in pigs [56].

\section{Co-overexpression of all OPN isoforms exists in primary EACs}

Upon further examination of SPP1 in the NCBI database (http://www.ncbi.nlm.nih.gov/gene/6696), we noted multiple isoforms of the gene and asked whether their expression/overexpression was transcriptionally exclusive in EAC. Using specific OPN primers flanking the OPN exons 5 and 6 in single-tube $\left[\gamma^{32} \mathrm{P}\right]$ ATP endlabeling RT-PCR reactions and PAGE gel analysis, we found that three isoforms, OPNa, b and c, were cooverexpressed in the majority of primary EAC samples (Figure 2A). Each OPN isoform band was gel purified and its sequence confirmed. The more recently reported OPN isoforms 4 (OPN4) and 5 (OPN5) (NCBI GRCh37) were investigated using qRT-PCR with exon 4 specific-primers for isoform 5 and primers crossing exons 1 to 7 for sizeselectable qRT-PCR for isoform 4 in a cohort of 64 primary EACs (Figure 2B). We found that expression of both OPN4 and OPN5 were not only elevated in primary EACs as compared to normal and Barrett's samples but also co-overexpressed (Figure 2B). We further validated the co-overexpression of OPN isoforms using exome specific variant analysis using Affymetrix expression array ST 2.1 data for 124 primary EACs (Figure 3B). 

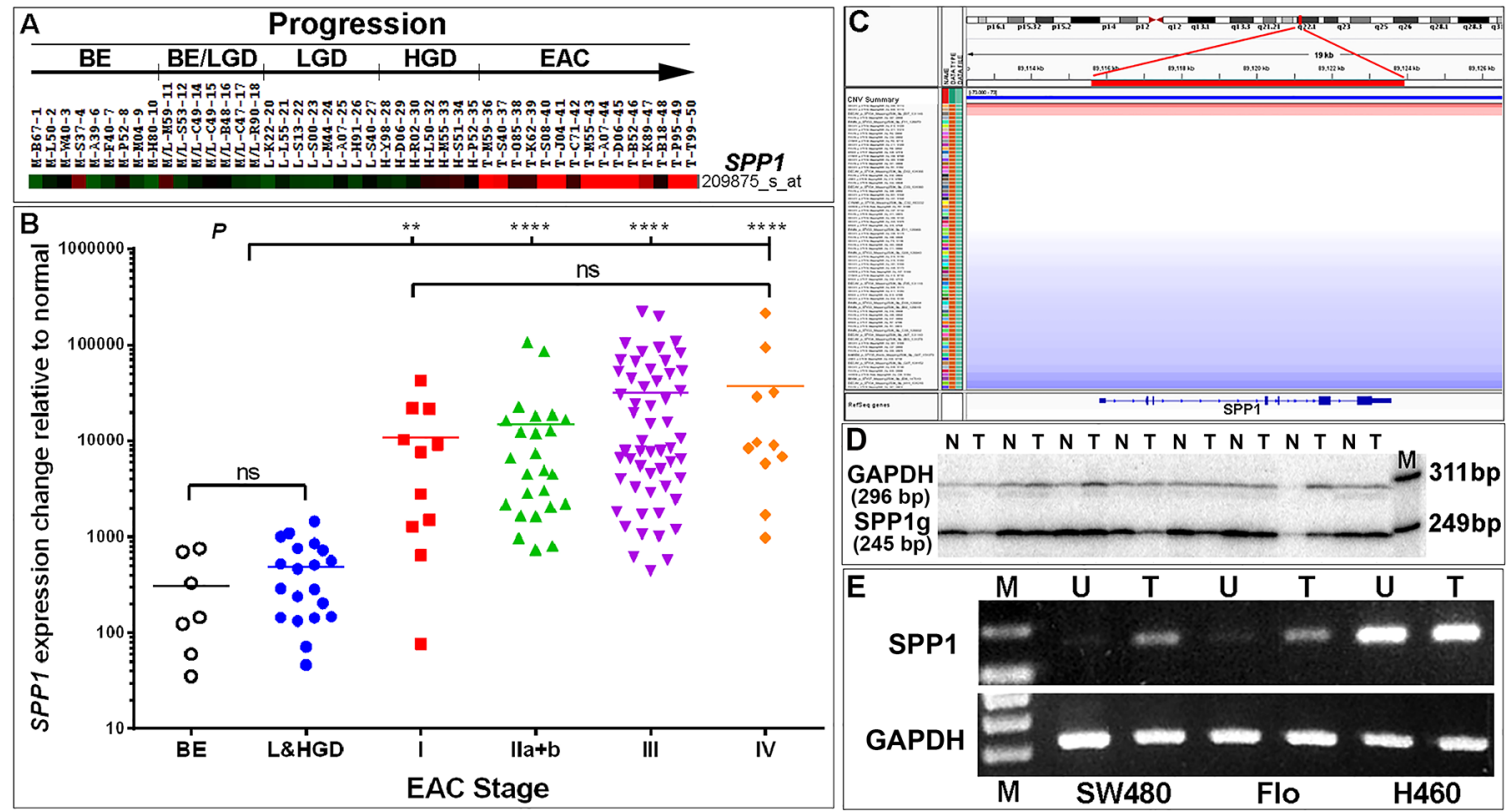

Figure 1: Transcriptional upregulation of $S P P 1 / O P N$ is a frequent event in EAC patients. A. An $S P P 1$-specific heatmap indicating highly overexpressed (red) SPP1 in EAC $(n=15)$ as compared with Barrett's esophageal metaplasia (BE) $(n=9)$, BE and low grade dysplasia $(\mathrm{BE} / \mathrm{LGD})(n=7)$, LGD $(n=8)$ and high grade dysplasia (HGD) $(n=7$, green or black) using Affymetrix U133A arrays. B. Overexpression of SPP1/OPN was validated in a cohort of 107 EACs using real-time RT-PCR analysis (Figure S1B-S1C). Significant elevated expression of SPP1/ OPN is found in all stages of EAC as compared to premalignant Barrett's metaplasia and dysplasia samples. There was a trend towards increasing expression of $S P P 1 / \mathrm{OPN}$ from early to advanced stage EAC; however, the change was not statistically significant (ns, not significant, $* * P<0.01$, $* * * * P<0.0001)$. C-D. Up-regulation of $S P P 1 / \mathrm{OPN}$ is not due to $S P P 1 / \mathrm{OPN}$ gene gain or amplification as assayed using SNP arrays in 73 primary EACs (red: DNA copy number gain; blue: DNA copy number loss; gray: DNA copy number unchanged) (C). SNP analysis of the chromosomal 4q22.1 region encompassing the SPP1/OPN gene in 73 EACs was visualized using Integrative Genomics Viewer (IGV) software (http:// www.broadinstitute.org/igv/). Unchanged copy number of the OPN locus was also confirmed by qPCR using single-tube co-amplification of SPP1 and GAPDH as an internal control end-labeled with $\left[\gamma_{-}{ }^{32} \mathrm{P}\right]$-ATP forward primers in 86 (including the 73 EACs analyzed in SNP arrays) paired normal-EAC samples. Matched pairs of normal-EAC qPCR products ( $244 \mathrm{bp}$ ) were resolved using $8 \%$ PAGE and a representative image shown (n, normal; t, tumor; M, loading marker with 311- and 249-bp bands shown) (D). E. OPN expression can be regulated via epigenetic modulation. Endogenous SPP1 levels were low in Flo and SW480 (colon carcinoma) cells but were highly abundant in H460 cells (large cell lung carcinoma) (see also Figure S2A). Cells were treated with 5-Aza-2'-deoxycytidine (decitabine) for $48 \mathrm{~h}$, RNA was isolated and reverse-transcribed followed by RT-PCR using SPP1 exon 7-8-specific primers (Table S1). PCR products were resolved on 1\% agarose gels (U, untreated; T, treated with decitabine).

All OPN isoforms were highly overexpressed and significantly correlated (Figure $3 \mathrm{~A}-3 \mathrm{E}$ ). Exon 4 is unique to the OPN5 isoform and, therefore, showed lower relative expression compared to the other exons (Figure 3B-3D). A probe set specific for OPN exon 6, which is expressed in isoforms OPNa, OPNc and OPN5 (Figure 3A), was not available in this Affymetrix ST 2.1 array. Using the mean of three probe sets (exons 7 and 8 ) that represented total OPN expression and that had the smallest deviations to differentiate the specific isoforms, we were able to determine the combined isoform expression levels across EACs and to show significant correlation between the isoform groups (Figure 3D-3E). We have demonstrated that the five OPN isoforms are concurrently overexpressed in primary EACs. These data also suggest that OPN isoforms may be subject to differential transcriptional regulation, as OPNc expression was less abundant compared to OPNa and OPNb in the majority of EACs while $\mathrm{OPNb}$ expression was higher, lower or equal to OPNa in individual EACs (Figure 2A).

\section{Overexpression of OPN was confirmed using tissue microarrays (TMA)}

A TMA analyzed with an OPN antibody (Osteopontin O-17, recognizing amino acids 17-31 of exons 2 and 3 within isoforms OPNa, b, c and 4) revealed abundant cytoplasmic staining, nuclear staining or both in a subset of EAC cells that were found to have very high transcriptional expression of OPN (Figure 4). OPN protein staining tended to be homogeneously strong across positive EAC lesions. Interestingly, in premalignant esophageal dysplasia, OPN staining was predominantly localized within stromal cells beneath the dysplastic epithelia rather than in the epithelial cells themselves (Figure 4).

\section{Ectopic expression of individual OPN isoforms in EAC cells lacking endogenous OPN expression}

Having confirmed transcriptional co-expression of individual OPN isoforms in primary EACs, we went on 


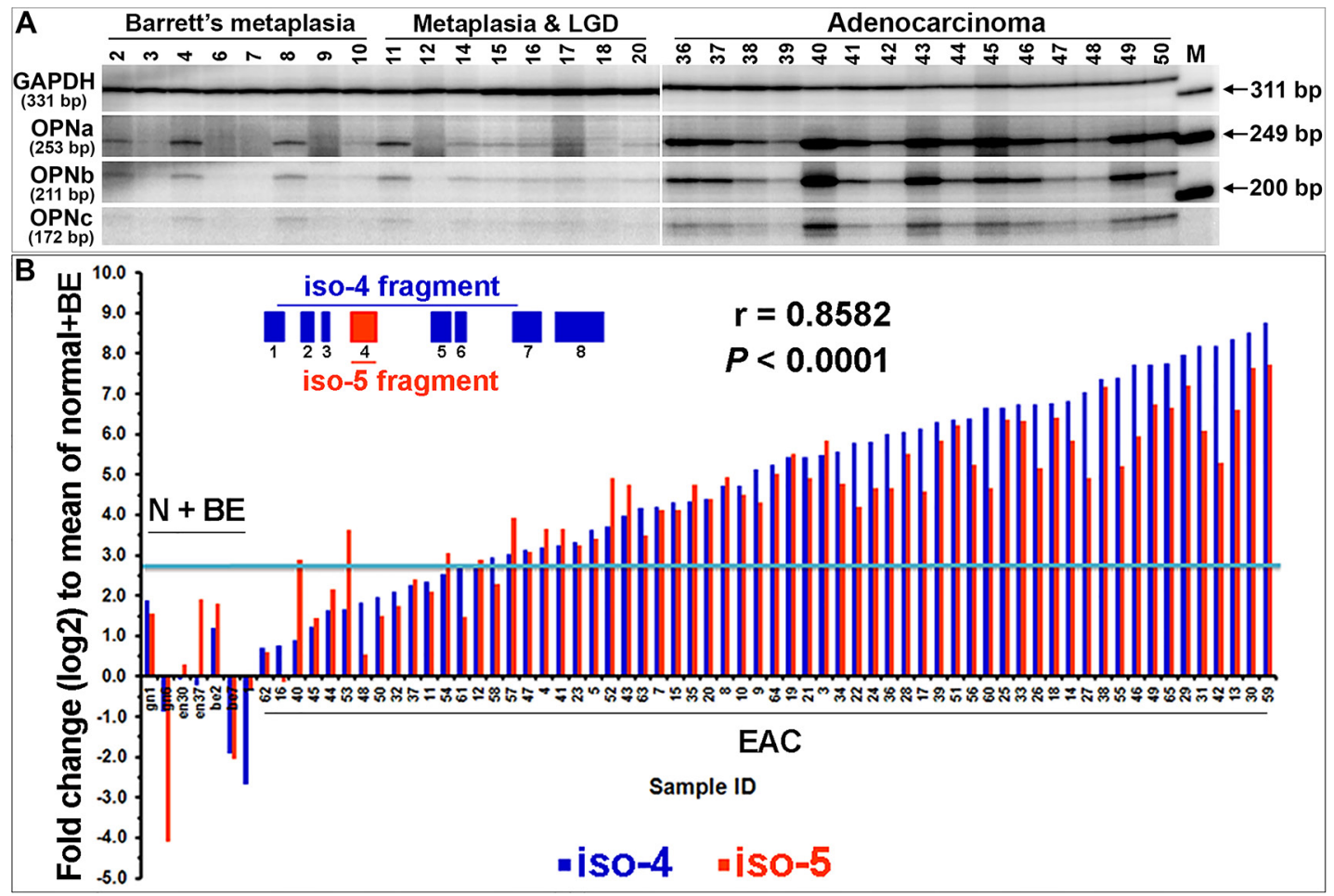

Figure 2: Co-overexpression of all five OPN isoforms in individual primary EACs. A. OPN isoforms a, b and $\mathrm{c}$ were co-overexpressed in EACs. Quantitative RT-PCR with a pair of primers flanking the SPP1/OPN exons 5 and 6 and a pair of primers for $G A P D H$ were co-amplified in a single-tube reaction using $\left[\gamma_{-}{ }^{32} \mathrm{P}\right]-\mathrm{ATP}$ labeling. Isoform fragments of OPNa (253 bp), b (211 bp) and c (172 bp), along with GAPDH (331 bp) were resolved by PAGE. B. Two sets of qRT-PCR analyses of OPN isoform 5-specific expression (primers located within exon 4) and OPN isoform 4 expression (size selection with primers crossing exons 1 to 7 ) were performed and a significant correlation was observed. The blue line indicates a 2-fold plus one standard deviation change as compared to the mean of normal and Barrett's metaplasia combined. (N, normal; BE, Barrett's esophagus)
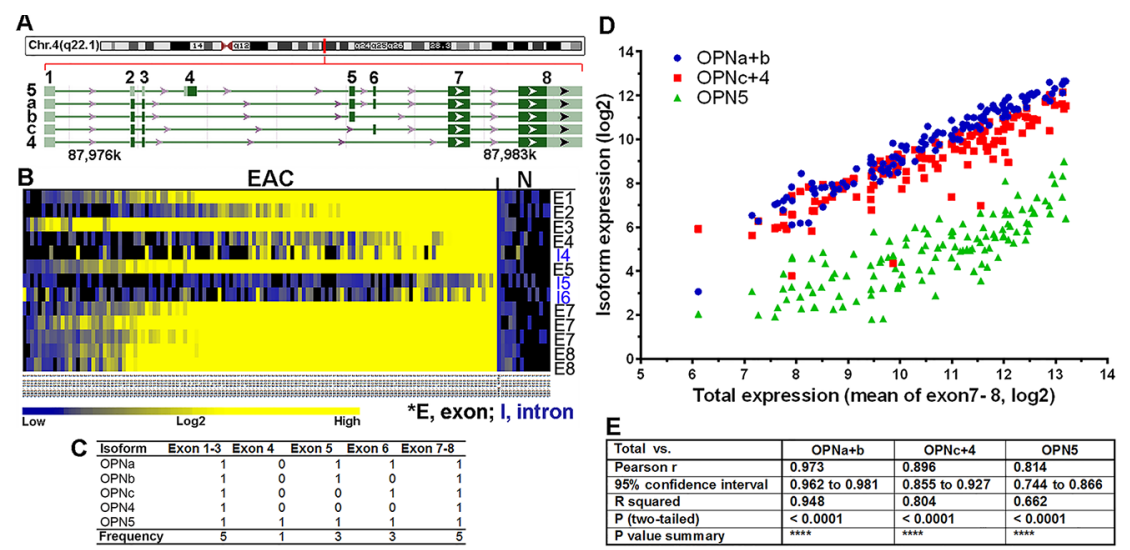

Figure 3: Transcriptional co-overexpression of all five OPN isoforms in primary EAC. A. SPP1 is located in chromosome 4q22.1, spanning $7.76 \mathrm{~kb}$ from 87.9756 to $87.9834 \mathrm{Mb}$ in the Contig NC 000004.12. Five isoforms are banked in genome build GRCh38. OPN5 is the only isoform that has exon 4 and an alternative start codon. OPNb lacks exon 6 while OPNc lacks exon 5. OPN4 is the isoform with the shortest transcript, lacking exons 4, 5 and 6. B. Heat map of exome variant analysis using ST 2.1 Affymetrix arrays of 124 primary EACs (exon 6 was not available in the ST 2.1 array). C. Summary of OPN isoform-specific exon expression (0, absence of exon/exons; 1, presence of exon/exons; Frequency, total number of times the exon/exons is expressed across all isoforms). D. Correlation of OPN isoform-specific expression in primary EAC. The mean expression derived from 3 probe sets ( 2 from exon 7 and 1 from exon 8 ) with the least deviation among all common exons (1, 2, 3, 7 and 8) was used to represent the total OPN expression. Subtraction of exon 5 expression (specific for isoforms OPNa, b and 5) from the total OPN expression yielded OPNc+4 expression (red dots). Subtraction of exon 4 expression, which was specific for OPN5 (green dots), from exon 5 expression yielded OPNa $+\mathrm{b}$ expression (blue dots). These expression levels were then plotted against the total OPN expression for each primary EAC in the arrays. E. Pearson correlation coefficients showed significant correlation between these groups. 


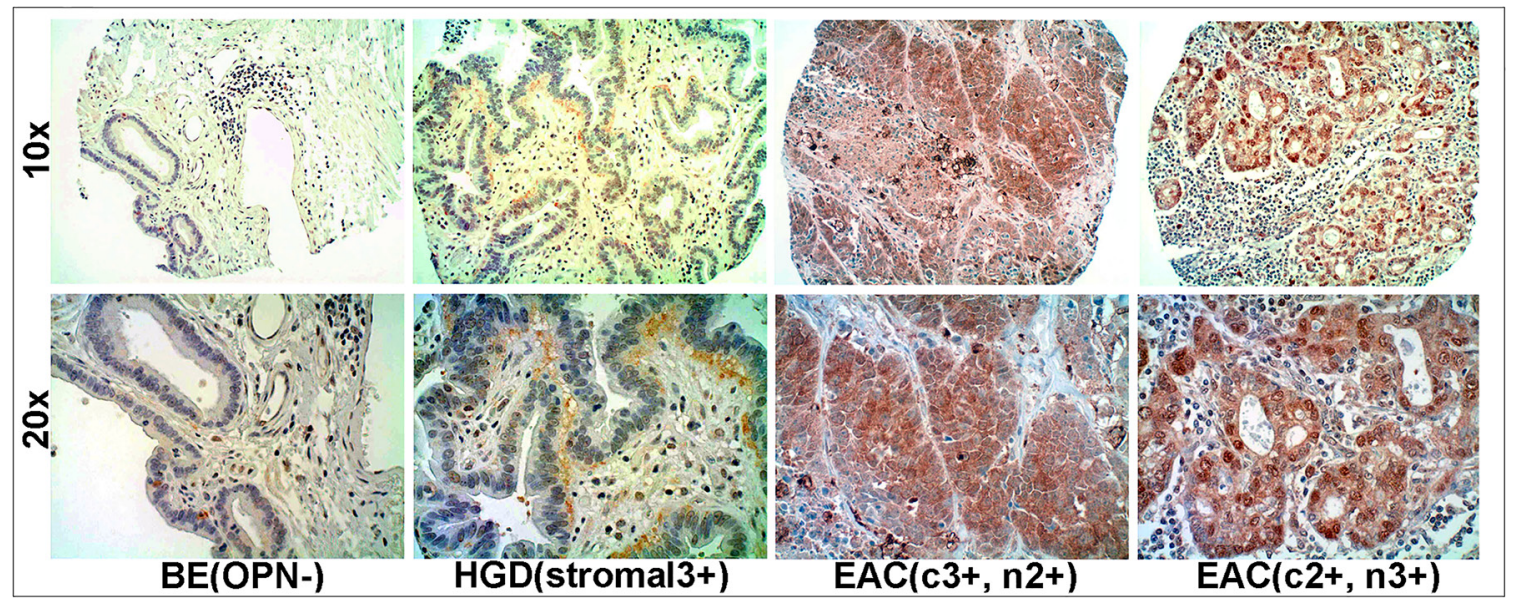

Figure 4: Overexpression of OPN protein in EAC using tissue microarray (TMA) immunohistochemistry. Overexpression of OPN protein was observed in EACs with differential intensity but homogeneous staining. Stroma adjacent to dysplastic epithelium but not the epithelial cells themselves, overexpressed OPN (c, cytoplasmic staining; n, nuclear staining).

to determine the functional similarities and differences of OPN isoforms in relation to tumor progression. We individually cloned each of three isoforms, $\mathrm{OPNa}, \mathrm{OPNb}$ and OPNc, into expression constructs using the OPN highly-expressing H460 (large cell lung carcinoma) cell line as the template (Figure 3A, Figure S2A-S2C). The EAC cell lines, Flo, OE33 and OE19, have low baseline endogenous levels of OPN (Figure S2A). Both Flo and OE33 cells were stably-transfected with each individual isoform (Figure S2B). Pooled transfectants of each isoform were cultured for $>10$ passages to ensure adaptation and consistent expression across experiments (Figure S2C-S2E). In addition, stable transfectants cloned at the thrombin cleavage site (R/SK) for the three isoforms were also established in Flo and OE33 cells, designated as OPNia, OPNib and OPNic lines (Figure S2B). These latter three transfectants include the integrin domains (RGD and SVVYGLR) but not the C-terminal CD44 domain.

\section{OPNb and OPNc act distinctly in cancer cell invasion and migration}

We observed that isoforms $\mathrm{OPNb}$ and $\mathrm{OPNc}$ contributed to a variety of distinctive phenotypes in cultured EAC cells as well as in EAC cell xenografts grown in nude mice. OPNb stable cells demonstrated significantly enhanced cell invasion in vitro as compared to OPNc cells in Matrigel assays (Figure 5A). When OE33/OPN isoform stable cells were labeled with luciferase, resuspended in Matrigel solution and injected into the flanks of nude mice, OPNb cells invaded Matrigel and grew into significantly larger xenografts in mice while OPNc cells failed to produce any tumor xenografts (Figure 5B). Expression levels of individual OPN isoforms were monitored in each experiment using qRT-PCR as represented in Figure 5A and Figure S2D-S2E.
OPN has been known to bind and activate both integrin and CD44 [28, 29, 33]. Both integrin and CD44 receptors are involved in cell adhesion, in which they lead to transduction of overlapping signaling pathways that mutually interact as an OPN-integrin-CD44 axis in tumor progression [15, 35, 37, 38]. To elucidate the specific functionality of each OPN isoform, we built not only full-length OPN isoforms $\mathrm{a}, \mathrm{b}$ and $\mathrm{c}$ expression vectors but also corresponding expression constructs lacking the CD44 domain, designated as OPNia, OPNib and OPNic (for integrin domain only isoforms OPNa, $\mathrm{b}$ and $\mathrm{c}$ ), which are endogenously produced following thrombin cleavage of full length isoforms at the RSK site. We found that $\mathrm{OPNb}$ cells took significantly less time to migrate into and to close a wound as compared to LacZ cells using the wound-healing assay (Figure 6A). Although slower than OPNb cells, OPNib cells similarly migrated much faster than LacZ cells, suggesting that the presence of the integrin domain of isoform $\mathrm{OPNb}$ is sufficient to sustain cell migration (Figure 6A). Moreover, migration of $\mathrm{OPNb}$ cells was attenuated when OPN antibody was present in the culture media (Figure S3A). Conversely, both OPNc and OPNic required extensively longer times or did not close the wound as compared to LacZ control cells (Figure 6A). OPNa cells closed the wound in a significantly shorter time than LacZ cells but migration of OPNia cells did not differ from LacZ control cells (Figure 6A). When OPN-null OE19 EAC cells were cultured with isoform-specific donormedia from individual Flo/OPN stable cells, OPNb-media promoted significantly more cell migration than $\mathrm{OPNc}$ media (Figure S3B) consistent with the results in OPN isoform-expressing stable cells (Figure 6A). Cilengitide is a cyclicized RGD pentapeptide that selectively and potently inhibits the major OPN integrin receptors $\alpha \mathrm{V} \beta 3$ and $\alpha \mathrm{V} \beta 5$. When wounded OPN stable cell cultures were treated with $100 \mathrm{nM}$ cilengitide, cell motility of OPNb cells 


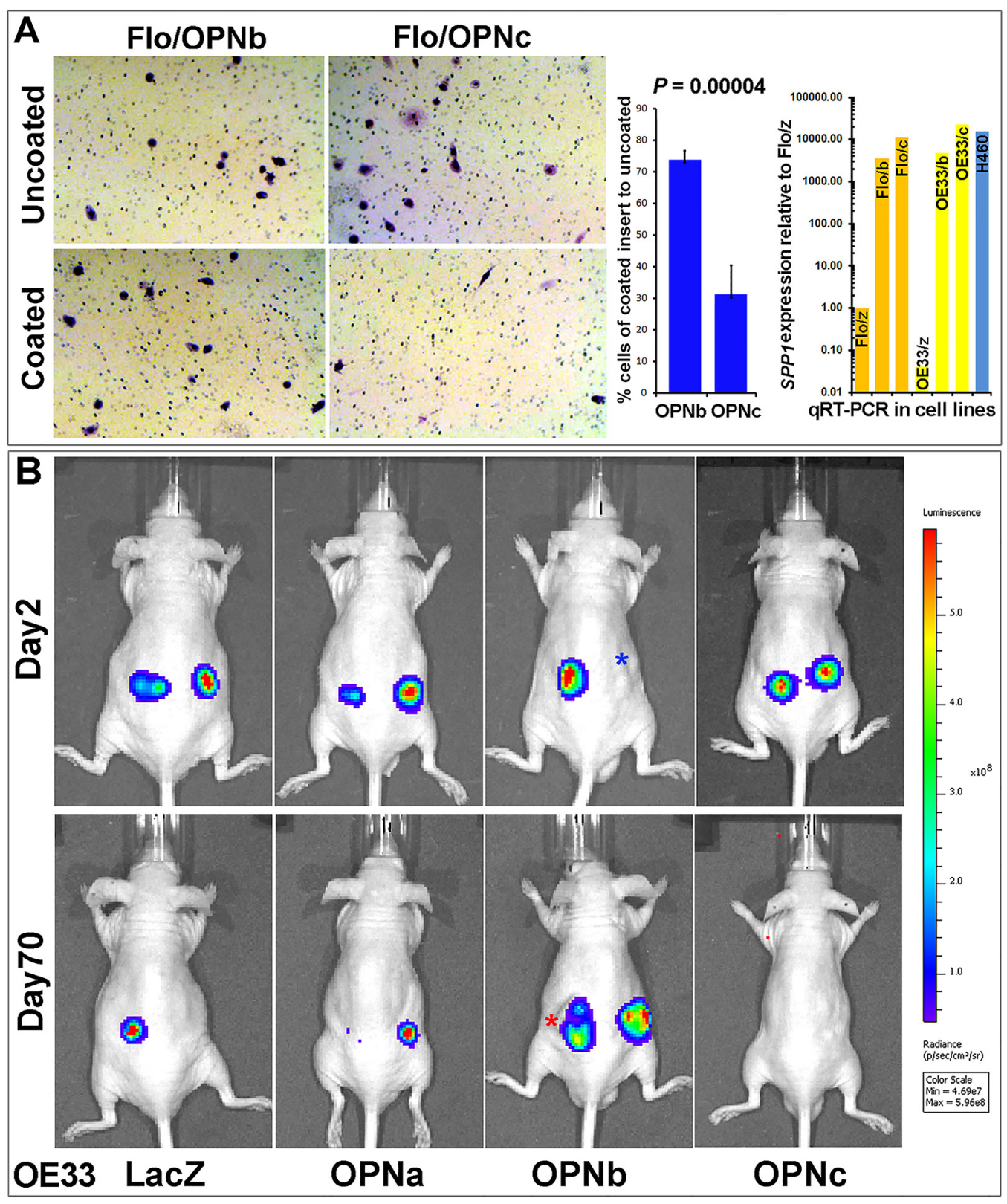

Figure 5: OPNb- and OPNc-expressing stable cells differ in cancer cell invasion. A. OPNb cells showed significantly more invasion than OPNc cells using Matrigel Basement Membrane Matrix-casted culture dishes ( $250 \mu \mathrm{g} / \mathrm{ml}$ of BD Matrigel Matrix) following 24-36 h incubation and Diff-Quick staining as compared with cells in non-casted culture dishes. OPN isoform expression levels were monitored using qRT-PCR. B. Matrigel Matrix-resuspended OPNb cells displayed more invasive growth and xenograft formation in vivo than OPNc cells. One million Lenti-Luc-labeled OE33/OPN stable cells were resuspended in $0.1 \mathrm{ml}$ Matrigel Matrix and subcutaneously injected into the flanks of nude mice. In vivo tumor imaging to monitor growth was performed using a Xenogen IVIS Spectrum scanner (*Note, red asterisk, actual imaging intensity should be greater than the reported measurement (total flux, $\mathrm{p} / \mathrm{s}$ ) due to tumor ulceration; blue asterisk, nodule at the site of subcutaneous injection but luciferin signal not detected).

was attenuated whereas the migration of OPNib cells was severely hindered (Figure 6B). The decreased cell mobility of OPNc and OPNic cells did not change following cilengitide treatment (Figure 6B). While mobility of OPNia cells also remained unchanged by integrin inhibition, migration of OPNa cells was reduced as compared to treated LacZ cells and untreated OPNa cells (Figure 6B). These results suggest that $\mathrm{OPNb}$-enhanced cell motility is strongly dependent on integrin binding as evidenced by both the significant increase in and subsequent cilengitideeffected abrogation of cell migration in OPNib cells. These data also suggest that OPNa isoform-induced cell motility is weaker than OPNb-mediated cell migration and that CD44 is necessary along with integrin signaling to sustain this mobility, supported by the similar migration of OPNia and LacZ control cells and reduced OPNa cell migration 


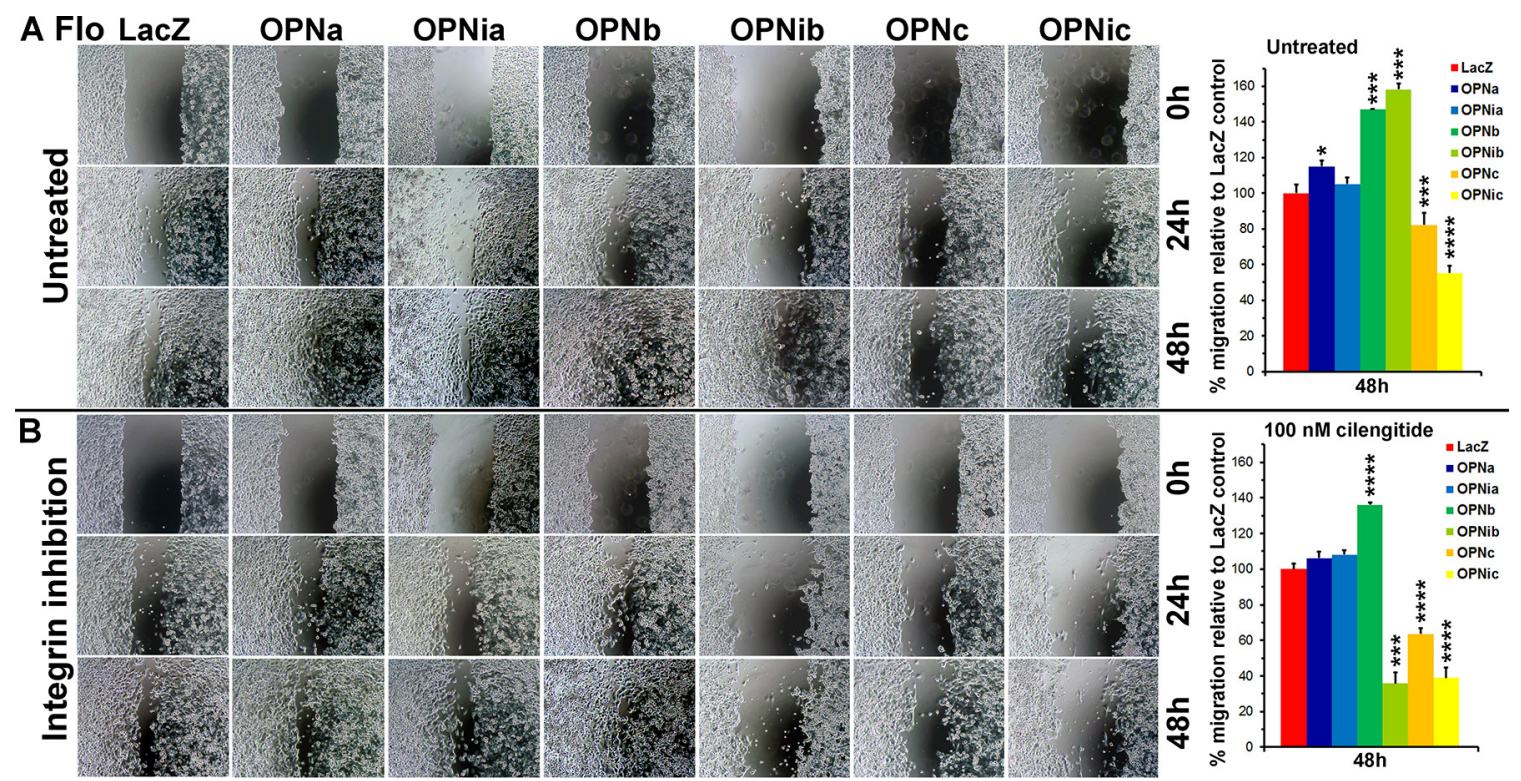

Figure 6: OPN isoform-expressing stable cells differ in cell migration and their response to RGD integrin inhibition. Flo/ OPN stable cells were seeded at $0.6 \times 10^{6}$ cells/12-well, wounded and cultured in media in the presence or absence of cilengitide (100 nM) up to $96 \mathrm{~h}$ post wounding. A. In the absence of cilengitide, both OPNb and OPNib cells showed significantly increased migration as compared to LacZ control cells. Both OPNc and OPNic cells were significantly less motile, with gaps remaining more than $96 \mathrm{~h}$ post wounding. OPNa cells showed increased migration as compared to LacZ control cells whereas OPNia cells demonstrated similar migration to LacZ cells. B. In the presence of cilengitide, OPNb cell motility was attenuated while OPNib cell migration was severely hindered. Reduced migration of OPNc and OPNic cells remained unchanged. Increased motility of OPNa cells was also attenuated but OPNia cell migration was similar to LacZ cells $(* P<0.05, * * * P<0.001, * * * * P<0.0001, t$-test $)$.

upon integrin inhibition. Stable expression of OPNc significantly reduced cell motility and these cells did not respond to integrin inhibition.

\section{OPNb cells exhibit significantly increased cell adhesion while OPNc cells show enhanced cell detachment}

We observed that OE33/OPNc cells required shorter trypsinization time than $\mathrm{OPNb}$ cells and that they significantly detached in culture when grown to semiconfluence as compared to LacZ and OPNb stable cells (Figure S4A). We found that these detached cells were able to grow in culture after collection and replating. This distinct OPNc phenotype may be explained by what we found in OE19 cells that were chronically treated with OPNc-media (Figure S4B). When diluted OPN-null OE19 cells were chronically cultured with OPN isoform-specific donormedia collected and filtered from Flo/LacZ, OPNa, OPNb and OPNc stable cells, most OE19 cells treated with LacZ, $\mathrm{OPNa}$ and $\mathrm{OPNb}$ donor-media grew as single-layered foci whereas most OE19 cells cultured with Flo/OPNc-media exhibited multi-layered spherical-shaped foci (Figure S4B). We further assessed cell adhesion in OPNb and OPNc cells using adhesion assays and found that OPNb cells were significantly more adherent to laminin-coated culture dishes than OPNc and LacZ cells (Figure 7A). Treatment of OPNb cells with the integrin inhibitor cilengitide abrogated this increased adhesion (Figure 7B). OPNib cells also showed enhanced cell adhesion, indicating that OPNb-mediated integrin signaling alone supports increased cell adhesion (Figure 7B). Given that significant cell detachment was detected in OE33/OPNc (Figure S4A) but not Flo/OPNc stable cells, that gene amplification and amplification-related overexpression of both ERBB2 and MET occur in OE33 but not in Flo cells (Figure S4C) and that previous studies have demonstrated activation of MET by CD44v6 and integrins [57-61] and an invasive growth program resulting from MET signaling [62-64], we examined whether these amplifications affected the cell adhesion phenotype in OE33/ OPNc cells. We knocked down ERBB2 alone, MET alone or both together using siRNAs against these two genes in OE33/OPN cells. Treated cells were allowed to grow to confluence and then fixed and stained with the Diff-Quik Staining System (Figure 8). We observed that knockdown of ERBB2 did not change the phenotype; however, silencing of MET significantly enhanced cell detachment, which was evidenced by reproducibly-increased unstained areas in culture dishes containing OPNc cells treated with siMET as compared to untreated, mock-treated, non-target siRNAtreated, or siERBB2 treated cells (Figure 8A-8B). These results are consistent with the role of MET in invasive growth in that silencing of MET augments OPNc-induced cell detachment. In addition, we found that $\mathrm{OE} 33 / \mathrm{LacZ}$ but not OPNa or OPNb cells exhibited increased detachment upon the knockdown of $M E T$, indicating that $\mathrm{OPNa}$ and $\mathrm{OPNb}$ 


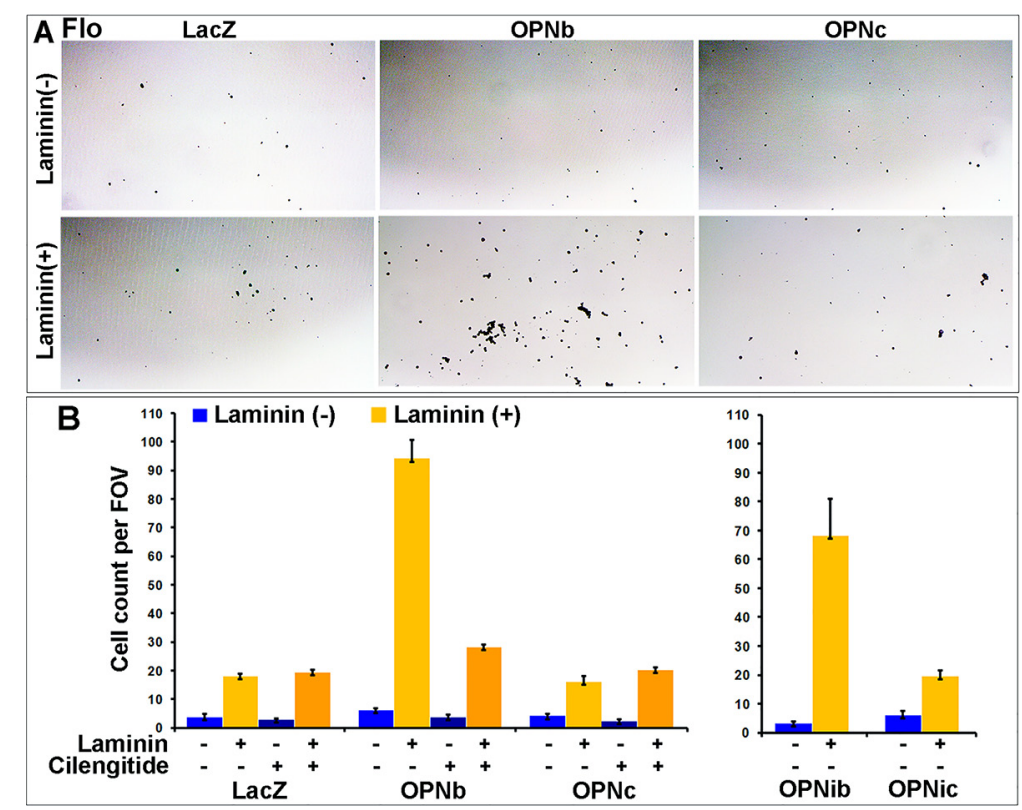

Figure 7: OPNb- and OPNc-expressing cells differ in cell adhesion and their response to RGD integrin inhibition. Culture plates were coated with Matrigel mixture (laminin at $10.8 \mu \mathrm{g} / \mathrm{ml}$ ), blocked for $30 \mathrm{~min}$, seeded with a single cell suspension $\left(0.01 \times 10^{6}\right.$ cells/96-well) and incubated at $37^{\circ} \mathrm{C} / 5 \% \mathrm{CO}_{2}$ for $30 \mathrm{~min}$. Cells were then fixed with glutaraldehyde and stained with Diff/Quick solution. A. Representative images demonstrating that OPNb significantly enhanced cell adhesion in laminin casted culture plates as compared to the LacZ control and OPNc stable cells. B. Enhanced cell adhesion was also observed for OPNib- but not OPNic-expressing cells. The significant increase in OPNb cell adhesion was abrogated with the addition of $1000 \mathrm{nM}$ cilengitide. (FOV, field of view)

enhanced cell adhesion to counteract cell detachment induced by the knockdown of MET (Figure 8B). Interestingly, OPNia stable cells were more detached than OPNa cells following treatment with siMET or siMET+siERBB2 whereas detachment in OPNic cells upon silencing of MET was more similar to the detachment seen in OPNc cells without siMET treatment (Figure 8A-8C). OPNib cells retained their adhesive properties when transfected with siMET (Figure 8C). The expression and efficiency of siRNA knockdown of ERBB2 and MET were monitored by qRTPCR. Cell adhesion/detachment assays were repeated and results were confirmed in three independent experiments.

These results suggest that OPNb strongly enhances cell adhesion and attachment in the presence or absence of CD44 signaling and that $\mathrm{OPNb}$-integrin signaling alone is sufficient to withstand siMET-induced cell detachment. While OPNa sustains cell adhesion and attachment, the presence of the CD44 domain is required to antagonize siMET-induced cell detachment. While OPNc promotes cell detachment with or without CD44 signaling, the siMET-enhanced detachment of OPNc cells is likely CD44-dependent.

\section{Inhibition of RGD integrins significantly reduces 2-D clonal growth of OPNb stable cells only and does not change 3-D colony formation of EAC/ OPNb or OPNc cells}

An $\mathrm{IC}_{50(\mathrm{Lac})}$ dose of cilengitide significantly reduced the clonogenic survival of Flo/OPNb and OPNib cells but not OPNc or OPNic cells in regular 2-D culture dishes as compared to LacZ cells in clonogenic assays (Figure 9A-9B). Both Flo/OPNb and OPNc cells demonstrated significantly increased colony formation as compared to Flo/LacZ control cells in soft agar assays (Figure 9C). Interestingly, this enhanced colony formation was not affected in both $\mathrm{OPNb}$ and OPNc cells when cultured in 3-D soft-agar in the presence or absence of $1000 \mathrm{nM}$ cilengitide (Figure 9C-9D).

These data further indicate that both $\mathrm{OPNb}$ and OPNc enhance cellular anchorage-independent growth of transformed cells and that anchorage-independent growth is not affected by integrin inhibition. Conversely, we show that OPNb-mediated cell proliferation is integrindependent while OPNc most likely acts via an integrinindependent pathway.

\section{Differential expression of E-cadherin and vimentin is observed in individual OPN isoform stable cells}

Having observed altered adhesion and detachment phenotypes in OPN isoform-expressing stable cells, we wanted to know whether ectopic stable expression of OPN isoforms altered expression of other classes of adhesion molecules. We found that while E-cadherin expression was elevated in OPNa, OPNb, OPNib and OPNic stable cells as compared to LacZ cells, it was decreased in OPNc and OPNia cells (Figure 10A-10B). Expression of the mesenchymal marker vimentin was markedly increased 


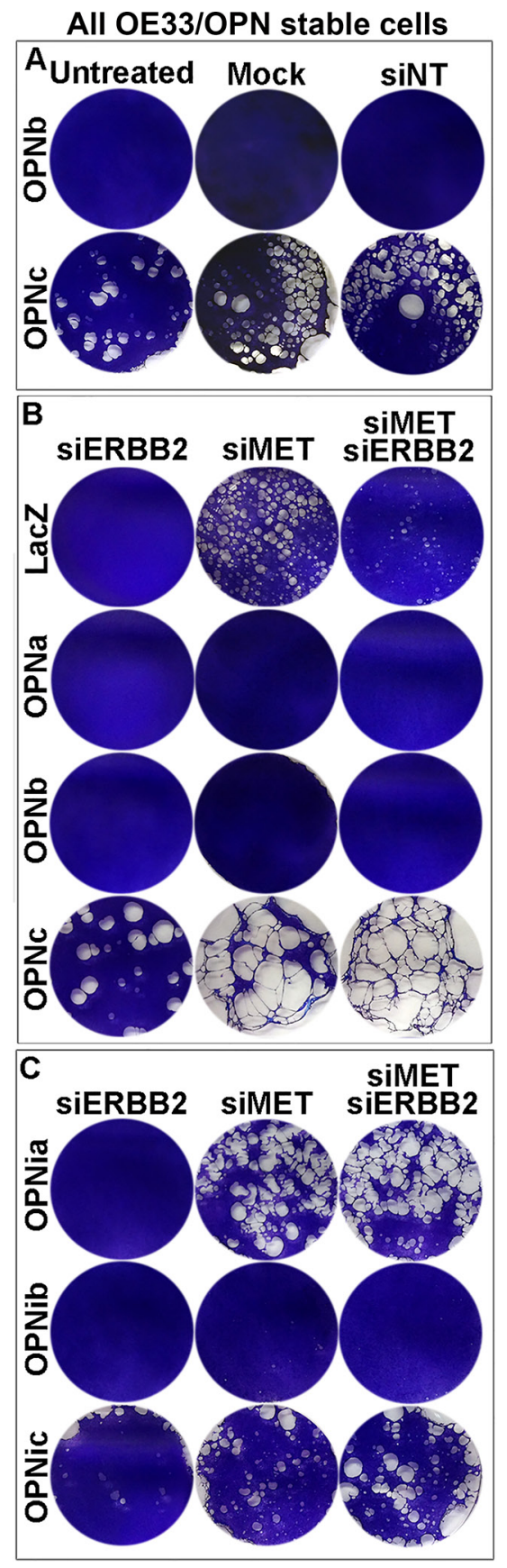

Figure 8: OPN isoform-expressing cells differ in cell detachment phenotypes that can be modulated by the $M E T$ oncogene. A. Significant cell detachment was observed for OE33/OPNc-expressing cells. OE33/OPN stable cells were seeded in culture dishes at $80 \%$ confluence $\left(0.22 \times 10^{6} \mathrm{cells} / \mathrm{ml}\right.$ in 6-well plates) for $24 \mathrm{~h}$, transfected with lipofectamine alone (mock) or siNonTarget (siNT) or untreated for $96 \mathrm{~h}$ and then fixed and stained with Diff-Quik staining solution. While OPNb-expressing cells demonstrated adherence to culture dishes, OPNc cells were significantly detached, as exhibited by markedly increased non-stained areas in culture dishes (see also Figure S4A). B. OE33 cells harbor both $M E T$ and ERBB2 gene amplification with corresponding gene overexpression (see Figure S4C). Silencing of MET using siRNA enhanced OE33/OPNc cell detachment while knockdown of ERBB2 did not alter its existing phenotype. Expression of both OPNa and $\mathrm{b}$ in OE33 cells appeared to increase adhesion of these cells, as control LacZ cells exhibited increased detachment following transfection with $10 \mathrm{nM}$ siMET or co-transfection with $5 \mathrm{nM}$ each siMET and siERBB2 as compared to transfection with $10 \mathrm{nM}$ siERBB2 alone. C. Silencing of MET resulted in significant detachment of OPNia-expressing cells but did not change the phenotypes of OPNib or OPNic-expressing cells as compared to their full-length OPN counterparts treated with siMET. 


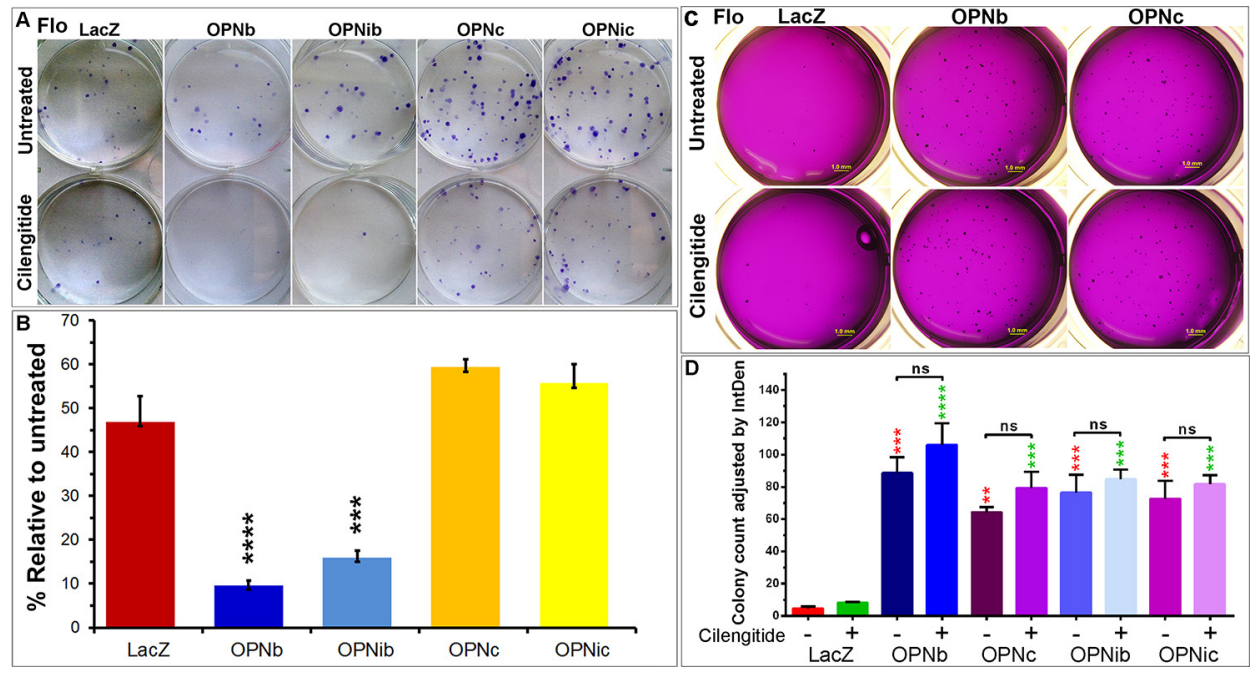

Figure 9: Integrin inhibition differentially influences cell growth in 2-D and 3-D cultures of OPNb- and OPNc-expressing cells. A. Cilengitide reduces OPNb but not OPNc cell proliferation in 2-D cultures. Representative plates were shown. OPNb, OPNib, OPNc, OPNic stable and LacZ control cells were seeded in sextuplicate at 150 cells/6-well. Sets of 3 wells were mock-treated or treated with $\mathrm{IC}_{50 \mathrm{LacZ}}$ dose of cilengitide $(1000 \mathrm{nM})$ for 12 days, and clonal foci were fixed and stained with Diff-Quik Staining solution. B. Bar graph representation of stained foci showing significantly reduced $\mathrm{OPNb}$ and OPNib cell proliferation in the presence of cilengitide as compared to their untreated cells, which exceeded the $50 \%\left(\mathrm{IC}_{50 \mathrm{LacZ}}\right)$ reduction observed in treated LacZ control, OPNc or OPNic cells. $(* * * P<0.001, * * * * P<0.0001$, $t$-test) C. Ectopic expression of both OPNb and OPNc enhanced EAC cell colony formation in 3-D soft agar cultures. Integrin inhibition did not significantly alter the colony formation of these cells. Flo/OPN and LacZ control cells (7000 cells/12-well, from the same cell-suspensions in Figure 9A) were mixed with top-agar media in the presence or absence of cilengitide $(1000 \mathrm{nM})$ and were pipetted onto the casted base-agar with or without cilengitide. Cells were allowed to grow for 20 days with periodic replacement of the overlaid media with or without cilengitide. Agar plates were stained with $0.05 \%$ crystal violet in 50\% ethanol and imaged using the Leica MXFL III Stereo microscope; Olympus DP-70 digital camera at $\times 0.8$ magnification. Soft agar assays were performed in triplicate. D. Significantly increased colony-formation was observed in Flo/OPNb, OPNib, OPNc and OPNic cells as compared to Flo/LacZ controls and was not altered with the addition of cilengitide. Colonies were counted using ImageJ software, and graphs were generated using Prism software. (red, comparison to untreated LacZ; green, comparison to cilengitide-treated LacZ; ns, not significant; $* * P<0.01$, $* * * P<0.001$, $* * * * P<0.0001$, One-way ANOVA)

in OPNb and OPNib cells as compared to other isoform stable and LacZ control cells (Figure 10A). Increased $\beta$-catenin expression was found in OPNa, $\mathrm{b}$ and $\mathrm{c}$ relative to LacZ cells, with the lowest increase found in OPNc cells. In the presence of cilengitide, this upregulation of $\beta$-catenin as well as E-cadherin was slightly decreased in $\mathrm{OPNb}$ cells but unchanged in OPNa cells. Additionally, cilengitide treatment elevated the expression of E-cadherin and $\beta$-catenin in OPNc cells (Figure 10B). The differential expression of E-cadherin, $\beta$-catenin and vimentin in individual OPN isoform stable cells could contribute to the morphologic and functional differences observed in the OPN isoform-expressing stable cells.

\section{DISCUSSION}

Understanding the molecular basis underlying early invasion and metastasis of EAC may lead to new and more effective therapeutic interventions resulting in improvement in the prognosis of patients with EAC. Osteopontin (OPN) has been reported as a cytokinemediated cell adhesion and motility factor that likely acts via both CD44 and integrin receptors [29, 65]. Several studies have suggested that OPN potentiates site-specific metastasis and that secreted OPN, derived from aggressive cancer cell xenografts, instigates indolent tumor cells to actively grow in vivo $[15,25,66,67]$. Recently, it has been suggested that OPN may play a key role in maintaining stemness-like phenotypes in hepatocellular carcinoma (HCC) cell lines via $\alpha v \beta 3 / \mathrm{NF \kappa B} / \mathrm{HIF} 1 \alpha$ signaling [68]. We demonstrated here that OPN is highly and frequently overexpressed in primary EACs. Using conventional end-labeling quantitative RT-PCR and bioinformatic exome variant analysis of the Affymetrix array ST 2.1 in a large cohort of EACs, we showed that all five OPN isoforms are co-overexpressed in primary tumors. Systematic comparison analyses of EAC OPNb- and OPNc-transfected stable cells demonstrated distinct phenotypes in cell adhesion, migration, in vitro and in vivo invasion, cell detachment and proliferation. Our data also showed that while OPNb and OPNa functioned through integrin signaling, OPNc acted in an integrin-independent manner. These functional differences could be partially accounted for by variable expression of E-cadherin, $\beta$-catenin and vimentin in stable OPNa, OPNb and OPNc cells, respectively. Silencing of MET in $M E T$-amplified OE33/OPNc stable cells augmented OPNc-induced cell detachment, yet OPNb-enhanced cell adhesion was not 


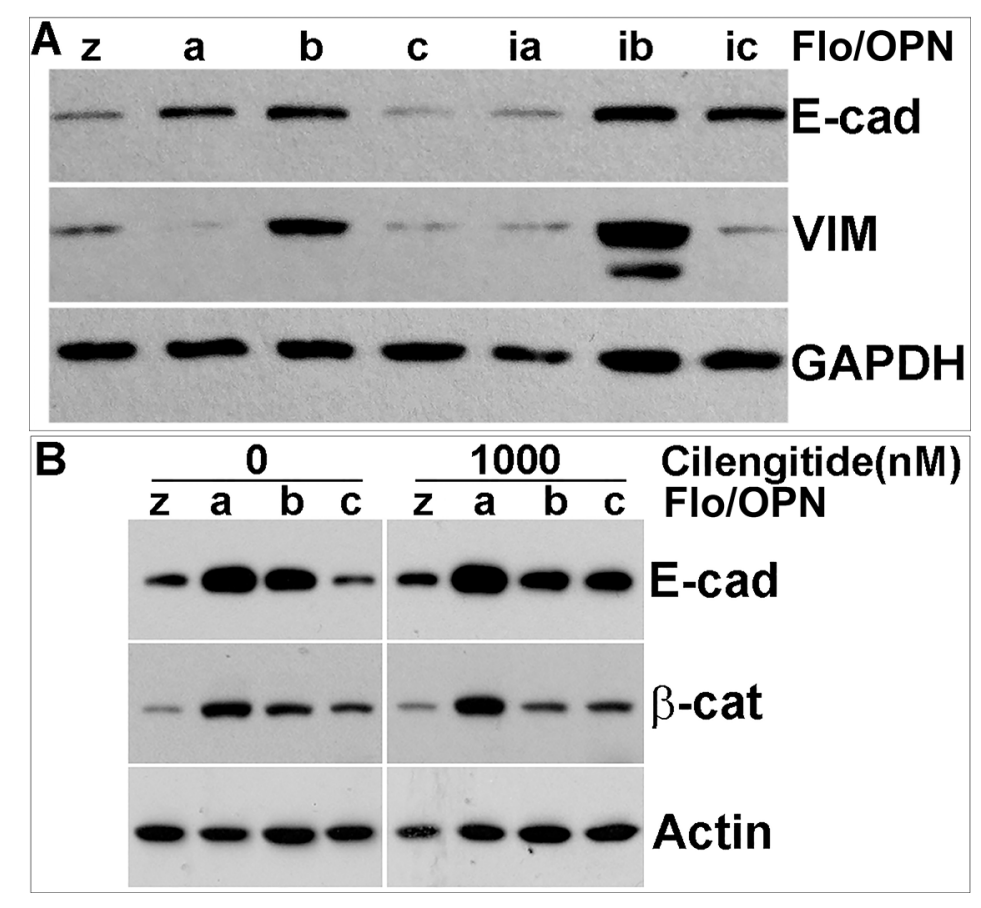

Figure 10: OPN isoform stable cells express different levels of WNT signaling- and EMT-related proteins. A. Western blot analysis revealed increased E-cadherin expression in OPNa-, OPNb-, OPNib- and OPNic-expressing cells but decreased expression in OPNc-and OPNia-expressing cells as compared to LacZ controls. Vimentin expression was increased in both OPNb- and OPNibexpressing cells but decreased in OPNa-, OPNia-, OPNc-, and OPNic-expressing cells. B. Elevated $\beta$-catenin expression was observed in OPNa-, OPNb- and OPNc-expressing cells. Addition of cilengitide did not alter $\beta$-catenin expression in any of the OPN isoform-expressing cells but induced E-cadherin expression in OPNc-expressing cells. GAPDH or $\beta$-actin was included as a loading control.

affected. While expression of both OPNb and OPNc in the transformed EAC cells significantly boosted the number of colonies formed in soft agar, blockade of integrin signaling did not affect their anchorage-independent growth. RGD integrin inhibition did, however, significantly reduce OPNb stable cell proliferation in 2-D cultures.

The finding that OPN is highly and frequently overexpressed in a large cohort of primary EACs at both the transcriptional and protein levels as reported here supports data from a previously reported expression profiling study of EAC and a multi-tumor analysis that included 10 cases of esophageal squamous carcinoma, 16 cases of pancreatic duct adenocarcinoma and 11 cases of gastric adenocarcinoma with OPN up-regulated in 70\%, $81 \%$ and $100 \%$ of cases, respectively $[48,69]$. Increased expression of OPN has also been identified in many other types of cancer and reported as either a biomarker or a functional regulator of cancer invasion and metastasis [28, 39, 70-73]. Since its identification in the late 1970's, OPN has been studied extensively as a cytokine and as a non-collagenous component of the extracellular matrix $[29,33,74,75]$. In the present study, we observed intense OPN staining predominantly in the primary EAC cells that had high RNA overexpression and only rare staining in the surrounding stromal matrix. In contrast, stromal cells adjacent to dysplastic epithelial cells showed much stronger OPN staining than the epithelial cells themselves.
The data suggest a switch in expression from the surrounding stroma to tumor cells during transformation from premalignant high grade dysplasia (HGD) to EAC. Copy number alterations were not related to SPP1/OPN overexpression. However, epigenetic mechanisms might influence OPN expression levels, as the hypomethylating agent decitabine induced OPN expression in endogenously low- or non-expressing EAC cells. Epigenetic modification of OPN has been previously reported using trichostatin A (TSA), a potent histone deacetylase (HDAC) inhibitor $[76,77]$. OPN has also been shown to be regulated by v-Src, PDGF, middle T antigen, and mechanically-induced reduction of methylation in the OPN promoter region [75-80]. Hormones, cytokines, and several other growth factors have been suggested to regulate OPN as well [33].

Five OPN isoforms have been reported in the GenBank database (http://www.ncbi.nlm.nih.gov/genbank/). With five transcriptionally spliced OPN isoforms, multiple post-translational modifications (phosphorylation, glycosylation and sulfation) and multiple functionallyactive proteolytic forms cleaved by thrombin, MMPs, plasmin and cathepsin D, OPN is a versatile modulator of many physiological and pathological processes, including cancer progression [33,81-87]. In this study, we attempted to address the question of whether these spliced isoforms are transcriptionally exclusive or inclusive in individual tumors, as previous evidence has been inconclusive [88]. 
We demonstrate that the five OPN isoforms, OPNa, OPNb, OPNc, isoform 4 and isoform 5, are co-upregulated in primary EACs. A previous study in hepatocellular cancer reported that OPNc was predominantly expressed in nonmalignant tissues and was associated with non-migratory phenotypes [89]. Our data suggest that OPNc not only reduces cell motility and enhances cell detachment but is also present in primary tumors. Our data also partially differ from a previous report in ovarian cancer that OPNc is the only tumor-specific isoform [90]. With all OPN isoforms cooverexpressed in EAC, the present study suggests that each OPN isoform has a distinct phenotype yet acts collectively to promote EAC progression. OPNb stable cells displayed enhanced cell proliferation, enhanced cell migration and invasion, yet sustained more cell adhesion. OPNc stable cells showed decreased cell migration and invasion but enhanced cell detachment. Stable expression of both OPNb and OPNc in EAC cells enhanced anchorage-independent growth in 3-D soft agar cultures. Some of these findings are consistent with previous observations in liver and breast cancers $[52,89]$. Although less than its full-length counterpart, motility of OPNb cells lacking the CD44 domain was still significantly greater than LacZ cells and other OPN isoform cells. Integrin inhibition in Flo/OPN isoform stable cells attenuated migration of OPNb cells but completely halted the migration of OPNb cells lacking the CD44 domain, strongly suggesting that $\mathrm{OPNb}$ is highly integrin-dependent. The finding that $\mathrm{OPNa}$ and $\mathrm{OPNb}$ are integrin signalingdependent while OPNc is integrin-independent has not been previously reported.

Interestingly, increased co-expression of E-cadherin and vimentin was observed in both $\mathrm{OPNb}$ and $\mathrm{OPNib}$ cells. While OPNa cells showed significantly increased E-cadherin and $\beta$-catenin, OPNc cells expressed minimal vimentin. Decreased E-cadherin and increased vimentin are indicative of epithelial-mesenchymal transition (EMT) in cancer, and elevated E-cadherin suppresses tumor invasion [91]. However, recent studies have reported that frequent, high level expression of E-cadherin is observed in colonized metastatic-cancer cells $[92,93]$ and that high expression of E-cadherin is associated with aggressive tumor growth [94]. Co-expression of epithelial proteins, such as E-cadherin, and mesenchymal markers, such as vimentin, has been observed in the majority of circulating tumor cells (CTC) of metastatic prostate and breast cancer patients [95].

In summary, we demonstrated that all five isoforms of the single gene, $S P P 1$, are co-expressed in the majority of primary EACs and act collectively in promoting tumor cell invasion and dissemination. Because all isoforms are co-expressed in primary tumors and function differently in the metastatic cascade, it is necessary to strategize a therapeutic targeting regimen aimed at both integrindependent and -independent OPN signaling cascades. Further investigation will be required to better characterize these critical isoform-signaling pathways in EAC.

\section{MATERIALS AND METHODS}

\section{Patients and EAC samples}

Written consent was obtained from all patients and the protocols received approval from the Institutional Review Board (IRB) at the University of Michigan. Tissues were obtained from patients undergoing esophagectomy for adenocarcinoma at the University of Michigan Health System between 1991 and 2011. Patients in this study had no preoperative radiation or chemotherapy unless otherwise noted. Specimens were fresh-frozen in liquid nitrogen and stored at $-80^{\circ} \mathrm{C}$ until use. Cellularity of metaplastic, dysplastic and tumor samples were determined by cryostat sectioning to be greater than $70 \%$ before DNA, RNA, or protein isolation. High molecular weight DNA was isolated as described previously with modifications [96]. RNA was isolated using the QIAGEN RNeasy Mini Kit and treated with DNase I following the manufacturer's instructions (QIAGEN). All DNA or RNA was quantified using the NanoDrop 3000 (NanoDrop Products). All RNA samples were subjected to gel electrophoresis or Bioanalyzer analysis for integrity assessment. Protein was isolated using lysis buffer (Cell Signaling Technology) with the addition of fresh protease inhibitor cocktail (SigmaAldrich). Lysates were centrifuged at $14,000 \mathrm{rpm}, 4^{\circ} \mathrm{C}$ for 20 minutes ( $\mathrm{min}$ ), and the supernatant was collected and stored at $-80^{\circ} \mathrm{C}$. Protein was quantified using the $D C$ Protein Assay Kit II (Bio-Rad) following the manufacturer's instruction and absorbance was read at $750 \mathrm{~nm}$ using an FLx800 Fluorescence Microplate Reader (BioTek, Winooski, VT).

\section{Affymetrix microarray assays}

Esophageal specimens, including nondysplastic and dysplastic Barrett's mucosa and EACs were subjected to gene expression profiling using Affymetrix U133A or ST 2.1 chips (Affymetrix, Santa Clara, CA) as previously described [97, 98]. Gene expression profiling data were deposited to the Gene Expression Omnibus (GEO) database (accession numbers: GSE37200 and GSE37201). A heat-map was computed and generated using Cluster and TreeView software (http://rana.lbl.gov/EisenSoftware.htm).

\section{Real-time RT-PCR (qRT-PCR) and $\left[\gamma-{ }^{32} P\right]$ -labeled quantitative RT-PCR analyses}

All PCR and RT-PCR primers were designed using the DNASTAR PrimerSelect software (DNASTAR, Inc. Madison, WI) and tested for specificity by gel electrophoresis (representative image in Figure S1A). Individual annealing temperatures were optimized using the Cepheid Smart Cycler (Cepheid). The melt curves of all qPCR or qRT-PCR reaction were closely monitored to avoid non-specific SYBR green signals (Figure S1B; 
Figure S2D-S2E). Copy number or gene fold changes were determined by the $2^{-\Delta \Delta \mathrm{Ct}}$ algorithm [99]. Duplicate reactions were performed by two or three individual researchers and the correlation analyzed (Figure S1B$\mathrm{S} 1 \mathrm{C})$. An index of 3 reference genes (GAPDH, ACTB, and $R P L P 0)$ [100] was applied to normalize the $2^{-\Delta \Delta \mathrm{Ct}}$-based assessments. All primer sequences used are listed in Table $\mathrm{S} 1$ or previously published [100]. Details for $\left[\gamma-{ }^{32} \mathrm{P}\right]-\mathrm{ATP}$ (NEN Life Science Products, Boston, MA) end-labeling for qRT-PCR analyses were as previously described [101]. The $\Phi$ X174 DNA/HinfI ladder was used as a reference (Promega).

\section{Immunohistochemistry of tissue microarrays (TMA)}

TMAs were constructed as previously described [102, 103]. Briefly, TMA arrays contained 122 cores from formalin-fixed paraffin-embedded tissue blocks from 73 EAC patients, including $63 \mathrm{EAC}, 18$ mixed EAC and dysplasia, 22 Barrett's metaplasia and dysplasia, 9 lymph node metastases and 10 from various types of normal tissue. TMA slides were hybridized with polyclonal OPN antibody (Cat. \# 915-034, clone O-17, Assay Designs Inc, Ann Arbor, MI) at a 1:750 dilution, following microwave citric acid epitope retrieval. Slides were lightly counterstained with hematoxylin. Each sample was then scored $0,1,2$, or 3 corresponding to absent, light, moderate, or intense staining by two individual researchers.

\section{Cell lines, culture conditions, cloning strategies and gene expression constructs}

The Flo cell line (derived from a stage IIB EAC patient in our laboratory) as well as both OE33 and OE19 cell lines (Sigma-Aldrich) were cultured in DMEM and RPMI media, respectively, supplemented with 10\% FBS and $1 \%$ antibiotic-antimycotic agent (GIBCO) unless otherwise noted. All cell lines and stable subclones were subjected to genotyping by the University of Michigan Sequencing Core facility to ensure cell line authenticity. Because endogenous expression of OPN in Flo, OE19 and OE33 EAC cell lines was low, cDNA from the high SPP1/OPN-expressing cell line H460, a large lung cell carcinoma line, was used as a template for PCR amplification of the individual OPN isoforms (Figure S2A-S2C). PCR products were then resolved in $1 \%$ TAE agarose gels, and individual isoforms were cut and purified (Figure S2A). Full-length OPNa, OPNb and OPNc products were ligated (T4 DNA ligase, New England BioLabs) into pcDNA4 (Invitrogen), and pooled, multi-clonal stable cells for each isoform were then cultured and maintained in selective zeocincontaining media (Figure S2B-S2C). LacZ was also cloned into pcDNA4 and selected with the same zeocincontaining media as a control. To achieve expression of the N-terminal integrin only fragments of OPNa, OPNb and OPNc that result from naturally thrombin cleavage at the R/SK site of OPN, isoform-specific PCR cloning products were designed with a stop codon immediately following this cleavage site and then individually cloned into the pcDNA4 vector (Figure S2B). These constructs were designated OPNia, OPNib and OPNic, with "i" indicting the integrin domain-containing only fragment. All expression vector constructs were sequenced to ensure the accuracy of gene inserts. OPN expression levels of each isoform in stable cells were monitored using qRTPCR (Figure S2D-S2E).

For assays evaluating epigenetic regulation of OPN expression, the demethylating agent 5-aza-2-deoxycytidine (5-Aza) was used at $5 \mu \mathrm{mol} / \mathrm{L}$ for 48 hours before cells were harvested and DNA was extracted.

\section{Invasion assay}

BD Matrigel (Cat. \# 354234, BD Bioscience) at 250 $\mu \mathrm{g} / \mathrm{ml}$ was thawed on ice and mixed with coating buffer (Tris $10 \mathrm{mM} \mathrm{pH} \mathrm{8.0,} \mathrm{NaCl} 0.7 \%$ ). The Matrigel mixture $(100 \mu \mathrm{l})$ was pipetted onto an $8 \mu \mathrm{m}$ pore insert of a 24 -well culture plate and incubated at $37^{\circ} \mathrm{C}$ for $>2$ hours (h). Cells were resuspended in serum-free medium at $0.045 \times 10^{6} \%$ $\mathrm{ml}$ and $0.5 \mathrm{ml}$ cells were seeded on the solidified Matrigel matrix. Bottom chambers were filled with $0.75 \mathrm{ml} \mathrm{10 \%}$ FBS media. Invasive cells were fixed and stained using the Diff-Quick kit (Fisher Scientific) and counted from five individual locations per insert and quantified using a ratio to matched migrating cells in uncoated wells per the manufacturer's instructions.

\section{Subcutaneous implantation of OPN stable isoform cells in nude mice}

Male nude mice at 6 weeks of age were purchased from Jackson Laboratory (Bar Harbor, Maine) and acclimated for one week before use. All mice were grouped in five or less animals per cage and maintained in the facilities of the Unit for Laboratory Animal Medicine (ULAM) with HEPA-filtered laminar flow rooms under specific pathogen-free conditions. All animal studies were conducted under the guidelines and approved protocols of the University Committee on Use and Care of Animals (UCUCA) of the University of Michigan. Following LentiLuc (University of Michigan Vector Core) transduction of all OPN isoform stable cells, $1 \times 10^{6}$ cells were resuspended in $100 \mu \mathrm{l}$ of $9 \mu \mathrm{g} / \mu \mathrm{l}$ BD Matrigel and injected subcutaneously into the flanks of nude mice. Mice were scanned with the IVIS Spectrum System (Perkin Elmer, Waltham, MA) 12 min after intraperitoneal administration of 3 luciferin/100 $\mu$ DPBS (Regis Technologies, Inc., Morton Grove, IL) at day 2 and day 70 post injection. A fixed region of interest (ROI) was applied to all tumors examined, and the ratio of total flux (photons/second, $\mathrm{p} / \mathrm{s}$ ) was calculated. 


\section{Integrin inhibition in Flo/OPN cells}

Cilengitide was purchased from Selleck Chemicals (Houston, TX) and dissolved in PBS at $33 \mu \mathrm{M}$. Flo/OPN cells were treated with cilengitide at a final concentration of $1000 \mathrm{nM}(600 \mathrm{ng} / \mathrm{ml})$ or vehicle control in $2 \%$ FBS media for 6 days, with cilengitide media changes every two days. Cells were allowed to recover in inhibitor-free $10 \%$ FBS media for $6 \mathrm{~h}$ and then retreated with inhibitorcontaining media for an additional $12 \mathrm{~h}$ prior to protein isolation.

\section{Wound healing assay}

Flo/OPN stable cells were seeded in triplicate at 0.6 $\times 10^{6}$ cells $/ 12$-well in $10 \%$ FBS DMEM and wounded at $24 \mathrm{~h}$ with p20 pipet tips. Cells were then cultured in $2 \%$ FBS DMEM containing $0.1 \%$ DMSO vehicle control or $100 \mathrm{nM}$ cilengitide in DMSO. Pictures were taken at 0 $\mathrm{h}, 12 \mathrm{~h}, 24 \mathrm{~h}, 48 \mathrm{~h}, 72 \mathrm{~h}$ and $96 \mathrm{~h}$ using a microscopemounted camera (SPOT Idea) and SPOT Software (SPOT Imaging Solutions, Sterling Heights, MI). Wound measurements were collected from 4 different areas per well at each time point for each individual OPN isoform, and migration distances were calculated.

\section{Gene knockdown using siRNA transfection}

$M E T$ and $E R B B 2$ gene amplification and expression levels were analyzed in OE33 and Flo cells using real time PCR and RT-PCR (Figure S3D). Primer sequences are listed in Table S1. OE33/OPN stable cells were plated at $0.6 \times 10^{6}$ cells/6-well and transfected with ON-TARGETplus siRNA (10 nM, unless otherwise noted) against MET (Cat. \# L-003156, Dharmacon), ERBB2 (Cat. \# L-003126, Dharmacon) or both (5 nM each) as well as control Non-Targeting siRNA (Cat. \# D-001210, Dharmacon) using Lipofectamine RNAiMAX (Invitrogen) at a final concentration of $1 \mu \mathrm{l} / \mathrm{ml}$ according to the manufacturers' instructions. Cells were cultured for $96 \mathrm{~h}$ with an addition of fresh siRNA at $48 \mathrm{~h}$. Mock transfections were performed using Lipofectamine RNAiMAX alone. Cells were then fixed and stained with Diff-Quick solutions per the manufacturer's instructions.

\section{Cell adhesion assays}

BD Matrigel (above mentioned), containing > $60 \%$ laminin, was thawed on ice and mixed with DPBS

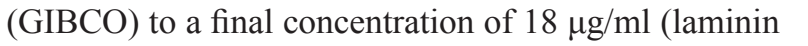
$10.8 \mu \mathrm{g} / \mathrm{ml}$ ). Tissue culture plates (96-well) were coated with $100 \mu 1 /$ well of Matrigel/DPBS mixture and DPBS was added to uncoated wells as controls. The plates were kept at room temperature for $60 \mathrm{~min}$ followed by aspiration of the supernatant DPBS solution. Blocking solution $(200 \mu \mathrm{l})$, containing $10 \mathrm{mg} / \mathrm{ml} \mathrm{BSA} / \mathrm{DPBS}$ that had been $0.22 \mu \mathrm{m}$ filtered and heat denatured at $85^{\circ} \mathrm{C}$ for $10 \mathrm{~min}$, was added to each well and incubated at room temperature for 30 min. Blocking solution was then aspirated and wells were washed once with $100 \mu \mathrm{l}$ DPBS. Single cell suspensions $\left(0.01 \times 10^{6}\right.$ cells/well $)$ in pre-gassed DMEM/HEPES (GIBCO) were plated in laminin-coated or uncoated 96well plates and incubated at $37^{\circ} \mathrm{C}, 5 \% \mathrm{CO}_{2}$ for $30 \mathrm{~min}$. Cell suspensions were then aspirated and $100 \mu \mathrm{l}$ of $5 \%$ glutaraldehyde $(\mathrm{w} / \mathrm{v})$ was added per well and incubated at room temperature for $30 \mathrm{~min}$ followed by three gentle washes with $100 \mu \mathrm{l}$ DPBS. Plates were then stained with Diff-Quick solution and cells were counted per FOV (field of view). Triplicate wells for each isoform and its uncoated control were analyzed in each experiment.

\section{Anchorage-independent growth and clonogenic assays}

Powdered DMEM and RPMI (Sigma-Aldrich) were purchased to make $2 x$ complete media with $20 \%$ FBS with or without $2 \times 1000 \mathrm{nM}$ of cilengitide. Both base-agar (1.3\%) and top-agar $(0.7 \%)$ were also made at $2 \mathrm{x}$ concentrations. Following equilibration in a $40^{\circ} \mathrm{C}$ water bath, base agar was mixed with $2 \mathrm{x}$ complete media with or without $2 \times 1000 \mathrm{nM}$ cilengitide in a 1:1 ratio, cast in triplicate wells of 12-well plates, and allowed to solidify at room temperature (RT) for $>1 \mathrm{~h}$. Similarly, top-agar and 2x media were mixed with single-cell suspensions of Flo/OPN (7000 cells/well) or OE33/OPN (5000 cells/well) stable cells, added to the solidified base-agar, and allowed to solidify for $30 \mathrm{~min}$ at RT. Plates were overlaid with complete media $(200 \mu \mathrm{l})$ and incubated at $37^{\circ} \mathrm{C} / 5 \% \mathrm{CO}_{2}$. A diluted aliquot of each cell group was plated in regular culture dishes $(150$ cells/ well in 6-well plates) to monitor cell counting and viability as well as the efficacy of $1000 \mathrm{nM}$ cilengitide, the predetermined $\mathrm{IC}_{50}$ dose for Flo/LacZ cells. Agar-plated cells and clonogenic-assayed cells were incubated at $37^{\circ} \mathrm{C} / 5 \%$ $\mathrm{CO}_{2}$ for 12 days (clonogenic assays) or 14-30 days (soft agar assays). Colonies were then stained with $0.05 \%$ crystal violet in $50 \%$ ethanol. Agar plate images were acquired using an Olympus DP-71 digital camera and Leica MXFL III stereo fluorescent microscope (Leica Microsystems). Colony numbers were quantitated using ImageJ software (http://rsb.info.nih.gov/ij/).

\section{Statistical analysis}

Graphs and Pearson correlation coefficients were generated using GraphPad Prism5 software (La Jolla, CA), and $p$-values were determined by log-rank test, $t$-test, and one-way or two-way ANOVA as appropriate.

\section{ACKNOWLEDGMENTS}

This work was supported by the Pilot Grant Program MICHR UL1TR000433, the University of Michigan Department of Surgery RAC award (LL) and the U54 
CA163059 (DGB and TDW) from the National Institutes of Health. The funders had no role in study design, data collection and analysis, decision to publish, or the preparation of the manuscript.

We thank Drs. Jinlu Dai and Evan Keller for access to and assistance with the IVIS Spectrum in vivo imaging system and software. We also thank the University of Michigan Core facilities: the DNA Sequencing Core for assistance with sample sequencing, genotyping and expression microarray processing; the Vector Core for providing the Lenti-Luc vector; and the Unit for Laboratory Animal Medicine (ULAM) for animal care services.

\section{CONFLICTS OF INTEREST}

The authors have declared no conflicts of interest.

\section{REFERENCES}

1. Devesa SS, Blot WJ, Fraumeni JF Jr. Changing patterns in the incidence of esophageal and gastric carcinoma in the United States. Cancer. 1998; 83:2049-2053.

2. Bollschweiler E, Wolfgarten E, Gutschow C, Holscher AH. Demographic variations in the rising incidence of esophageal adenocarcinoma in white males. Cancer. 2001; 92:549-555.

3. Brown LM, Devesa SS, Chow WH. Incidence of adenocarcinoma of the esophagus among white Americans by sex, stage, and age. J Natl Cancer Inst. 2008; 100:1184-1187.

4. Farrow DC, Vaughan TL. Determinants of survival following the diagnosis of esophageal adenocarcinoma (United States). Cancer Causes Control. 1996; 7:322-327.

5. Sihvo EI, Luostarinen ME, Salo JA. Fate of patients with adenocarcinoma of the esophagus and the esophagogastric junction: a population-based analysis. Am J Gastroenterol. 2004; 99:419-424.

6. Lagergren J, Bergstrom R, Lindgren A, Nyren O. Symptomatic gastroesophageal reflux as a risk factor for esophageal adenocarcinoma. N Engl J Med. 1999; 340:825-831.

7. Shaheen NJ, Richter JE. Barrett's oesophagus. Lancet. $2009 ; 373: 850-861$.

8. Orringer MB, Marshall B, Chang AC, Lee J, Pickens A, Lau CL. Two thousand transhiatal esophagectomies: changing trends, lessons learned. Ann Surg. 2007; 246:363-372. discussion 372-364.

9. van Hagen P, Hulshof MC, van Lanschot JJ, Steyerberg EW, van Berge Henegouwen MI, Wijnhoven BP, Richel DJ, Nieuwenhuijzen GA, Hospers GA, Bonenkamp JJ, Cuesta MA, Blaisse RJ, Busch OR, ten Kate FJ, Creemers GJ, Punt CJ, et al. Preoperative chemoradiotherapy for esophageal or junctional cancer. N Engl J Med. 2012; 366:2074-2084.
10. Eil R, Diggs BS, Wang SJ, Dolan JP, Hunter JG, Thomas CR. Nomogram for predicting the benefit of neoadjuvant chemoradiotherapy for patients with esophageal cancer: A SEER-Medicare analysis. Cancer. 2014; 120:492-8.

11. Sporn MB. The war on cancer. Lancet. 1996; 347:1377-1381.

12. Siegel R, Naishadham D, Jemal A. Cancer statistics, CA Cancer J Clin. 2013; 63:11-30.

13. Chambers AF, Groom AC, MacDonald IC. Dissemination and growth of cancer cells in metastatic sites. Nat Rev Cancer. 2002; 2:563-572.

14. Fidler IJ. The pathogenesis of cancer metastasis: the 'seed and soil' hypothesis revisited. Nat Rev Cancer. 2003; 3:453-458.

15. Gupta GP, Massague J. Cancer metastasis: building a framework. Cell. 2006; 127:679-695.

16. Chaffer CL, Weinberg RA. A perspective on cancer cell metastasis. Science. 2011; 331:1559-1564.

17. Reuter JA, Ortiz-Urda S, Kretz M, Garcia J, Scholl FA, Pasmooij AM, Cassarino D, Chang HY, Khavari PA. Modeling inducible human tissue neoplasia identifies an extracellular matrix interaction network involved in cancer progression. Cancer Cell. 2009; 15:477-488.

18. Joyce JA, Pollard JW. Microenvironmental regulation of metastasis. Nat Rev Cancer. 2009; 9:239-252.

19. Ungefroren H, Sebens S, Seidl D, Lehnert H, Hass R. Interaction of tumor cells with the microenvironment. Cell Commun Signal. 2011; 9:18.

20. Weaver VM, Lelievre S, Lakins JN, Chrenek MA, Jones JC, Giancotti F, Werb Z, Bissell MJ. beta4 integrin-dependent formation of polarized three-dimensional architecture confers resistance to apoptosis in normal and malignant mammary epithelium. Cancer Cell. 2002; 2:205-216.

21. Sherman-Baust CA, Weeraratna AT, Rangel LB, Pizer ES, Cho KR, Schwartz DR, Shock T, Morin PJ. Remodeling of the extracellular matrix through overexpression of collagen VI contributes to cisplatin resistance in ovarian cancer cells. Cancer Cell. 2003; 3:377-386.

22. Yang AD, Fan F, Camp ER, van Buren G, Liu W, Somcio R, Gray MJ, Cheng H, Hoff PM, Ellis LM. Chronic oxaliplatin resistance induces epithelial-to-mesenchymal transition in colorectal cancer cell lines. Clin Cancer Res. $2006 ; 12: 4147-4153$.

23. Wang Z, Li Y, Kong D, Banerjee S, Ahmad A, Azmi AS, Ali S, Abbruzzese JL, Gallick GE, Sarkar FH. Acquisition of epithelial-mesenchymal transition phenotype of gemcitabine-resistant pancreatic cancer cells is linked with activation of the notch signaling pathway. Cancer Res. 2009; 69:2400-2407.

24. Wang Z, Li Y, Ahmad A, Banerjee S, Azmi AS, Kong D, Sarkar FH. Pancreatic cancer: understanding and overcoming chemoresistance. Nat Rev Gastroenterol Hepatol. 2011; 8:27-33. 
25. Gupta GP, Minn AJ, Kang Y, Siegel PM, Serganova I, Cordon-Cardo C, Olshen AB, Gerald WL, Massague J. Identifying site-specific metastasis genes and functions. Cold Spring Harb Symp Quant Biol. 2005; 70:149-158.

26. Bhattacharya SD, Mi Z, Kim VM, Guo H, Talbot LJ, Kuo PC. Osteopontin regulates epithelial mesenchymal transition-associated growth of hepatocellular cancer in a mouse xenograft model. Ann Surg. 2012; 255:319-325.

27. Li NY, Weber CE, Mi Z, Wai PY, Cuevas BD, Kuo PC. Osteopontin up-regulates critical epithelial-mesenchymal transition transcription factors to induce an aggressive breast cancer phenotype. J Am Coll Surg. 2013; 217:17-26. discussion 26

28. Ruoslahti E, Pierschbacher MD. New perspectives in cell adhesion: RGD and integrins. Science. 1987; 238:491-497.

29. Weber GF, Ashkar S, Glimcher MJ, Cantor H. Receptorligand interaction between CD44 and osteopontin (Eta-1). Science. 1996; 271:509-512.

30. Smith LL, Cheung HK, Ling LE, Chen J, Sheppard D, Pytela R, Giachelli CM. Osteopontin N-terminal domain contains a cryptic adhesive sequence recognized by alpha9beta1 integrin. J Biol Chem. 1996; 271:28485-28491.

31. Bayless KJ, Meininger GA, Scholtz JM, Davis GE. Osteopontin is a ligand for the alpha4beta1 integrin. Journal of cell science. 1998; 111:1165-1174.

32. Yokosaki Y, Matsuura N, Sasaki T, Murakami I, Schneider H, Higashiyama S, Saitoh Y, Yamakido M, Taooka Y, Sheppard D. The integrin alpha(9)beta(1) binds to a novel recognition sequence (SVVYGLR) in the thrombin-cleaved amino-terminal fragment of osteopontin. The Journal of biological chemistry. 1999; 274:36328-36334

33. Sodek J, Ganss B, McKee MD. Osteopontin. Crit Rev Oral Biol Med. 2000; 11:279-303.

34. Barry ST, Ludbrook SB, Murrison E, Horgan CM. A regulated interaction between alpha5beta1 integrin and osteopontin. Biochemical and biophysical research communications. 2000; 267:764-769.

35. Katagiri YU, Sleeman J, Fujii H, Herrlich P, Hotta H, Tanaka K, Chikuma S, Yagita H, Okumura K, Murakami M, Saiki I, Chambers AF, Uede T. CD44 variants but not CD44s cooperate with beta1-containing integrins to permit cells to bind to osteopontin independently of arginine-glycine-aspartic acid, thereby stimulating cell motility and chemotaxis. Cancer Res. 1999; 59:219-226.

36. Felding-Habermann B, O'Toole TE, Smith JW, Fransvea E, Ruggeri ZM, Ginsberg MH, Hughes PE, Pampori N, Shattil SJ, Saven A, Mueller BM. Integrin activation controls metastasis in human breast cancer. Proc Natl Acad Sci U S A. 2001; 98:1853-1858.

37. Ponta H, Sherman L, Herrlich PA. CD44: from adhesion molecules to signalling regulators. Nat Rev Mol Cell Biol. 2003; 4:33-45.

38. Guo W, Giancotti FG. Integrin signalling during tumour progression. Nat Rev Mol Cell Biol. 2004; 5:816-826.
39. Wai PY, Kuo PC. Osteopontin: regulation in tumor metastasis. Cancer Metastasis Rev. 2008; 27:103-118.

40. Weber GF. The metastasis gene osteopontin: a candidate target for cancer therapy. Biochim Biophys Acta. 2001; 1552:61-85.

41. Jain S, Chakraborty G, Bulbule A, Kaur R, Kundu GC. Osteopontin: an emerging therapeutic target for anticancer therapy. Expert Opin Ther Targets. 2007; 11:81-90.

42. Chien CY, Tsai HT, Su LJ, Chuang HC, Shiu LY, Huang CC, Fang FM, Yu CC, Su HT, Chen CH. Aurora-A signaling is activated in advanced stage of squamous cell carcinoma of head and neck cancer and requires osteopontin to stimulate invasive behavior. Oncotarget. 2014; 5:2243-2262.

43. Ogbureke KU, Weinberger PM, Looney SW, Li L, Fisher LW. Expressions of matrix metalloproteinase-9 (MMP-9), dentin sialophosphoprotein (DSPP), and osteopontin (OPN) at histologically negative surgical margins may predict recurrence of oral squamous cell carcinoma. Oncotarget. 2012; 3:286-298.

44. Hourihan RN, O'Sullivan GC, Morgan JG. Transcriptional gene expression profiles of oesophageal adenocarcinoma and normal oesophageal tissues. Anticancer Res. 2003; 23:161-165.

45. Hao Y, Triadafilopoulos G, Sahbaie P, Young HS, Omary MB, Lowe AW. Gene expression profiling reveals stromal genes expressed in common between Barrett's esophagus and adenocarcinoma. Gastroenterology. 2006; 131:925-933.

46. Wang S, Zhan M, Yin J, Abraham JM, Mori Y, Sato F, Xu Y, Olaru A, Berki AT, Li H, Schulmann K, Kan T, Hamilton JP, Paun B, Yu MM, Jin Z, et al. Transcriptional profiling suggests that Barrett's metaplasia is an early intermediate stage in esophageal adenocarcinogenesis. Oncogene. 2006; 25:3346-3356.

47. Greenawalt DM, Duong C, Smyth GK, Ciavarella ML, Thompson NJ, Tiang T, Murray WK, Thomas RJ, Phillips WA. Gene expression profiling of esophageal cancer: comparative analysis of Barrett's esophagus, adenocarcinoma, and squamous cell carcinoma. Int J Cancer. 2007; 120:1914-1921.

48. Kim SM, Park YY, Park ES, Cho JY, Izzo JG, Zhang D, Kim SB, Lee JH, Bhutani MS, Swisher SG, Wu X, Coombes KR, Maru D, Wang KK, Buttar NS, Ajani JA, et al. Prognostic biomarkers for esophageal adenocarcinoma identified by analysis of tumor transcriptome. PLoS One. 2010; 5:e15074.

49. Nancarrow DJ, Clouston AD, Smithers BM, Gotley DC, Drew PA, Watson DI, Tyagi S, Hayward NK, Whiteman DC. Whole genome expression array profiling highlights differences in mucosal defense genes in Barrett's esophagus and esophageal adenocarcinoma. PLoS One. 2011; 6:e22513.

50. Miller CT, Lin L, Casper AM, Lim J, Thomas DG, Orringer MB, Chang AC, Chambers AF, Giordano TJ, 
Glover TW, Beer DG. Genomic amplification of MET with boundaries within fragile site FRA7G and upregulation of MET pathways in esophageal adenocarcinoma. Oncogene. 2006; 25:409-418.

51. Shanmugam V, Chackalaparampil I, Kundu GC, Mukherjee AB, Mukherjee BB. Altered sialylation of osteopontin prevents its receptor-mediated binding on the surface of oncogenically transformed tsB77 cells. Biochemistry. 1997; 36:5729-5738.

52. He B, Mirza M, Weber GF. An osteopontin splice variant induces anchorage independence in human breast cancer cells. Oncogene. 2006; 25:2192-2202.

53. Ivanov SV, Ivanova AV, Goparaju CM, Chen Y, Beck A, Pass HI. Tumorigenic properties of alternative osteopontin isoforms in mesothelioma. Biochem Biophys Res Commun. 2009; 382:514-518.

54. Gimba ER, Tilli TM. Human osteopontin splicing isoforms: known roles, potential clinical applications and activated signaling pathways. Cancer Lett. 2013; 331:11-17.

55. Dulak AM, Schumacher SE, van Lieshout J, Imamura Y, Fox C, Shim B, Ramos AH, Saksena G, Baca SC, Baselga J, Tabernero J, Barretina J, Enzinger PC, Corso G, Roviello F, Lin L, et al. Gastrointestinal adenocarcinomas of the esophagus, stomach, and colon exhibit distinct patterns of genome instability and oncogenesis. Cancer Res. 2012; 72:4383-4393.

56. Shen CJ, Tsou YA, Chen HL, Huang HJ, Wu SC, Cheng WT, Chen CY, Chen CM. Osteoponin promoter controlled by DNA methylation: aberrant methylation in cloned porcine genome. Biomed Res Int. 2014; 2014:327538.

57. van der Voort R, Taher TE, Wielenga VJ, Spaargaren M, Prevo R, Smit L, David G, Hartmann G, Gherardi E, Pals ST. Heparan sulfate-modified CD44 promotes hepatocyte growth factor/scatter factor-induced signal transduction through the receptor tyrosine kinase c-Met. J Biol Chem. 1999; 274:6499-6506.

58. Orian-Rousseau V, Chen L, Sleeman JP, Herrlich P, Ponta H. CD44 is required for two consecutive steps in HGF/c-Met signaling. Genes Dev. 2002; 16:3074-3086.

59. Hasenauer S, Malinger D, Koschut D, Pace G, Matzke A, von $\mathrm{Au} \mathrm{A}$, Orian-Rousseau V. Internalization of Met requires the co-receptor CD44v6 and its link to ERM proteins. PLoS One. 2013; 8:e62357.

60. Tuck AB, Elliott BE, Hota C, Tremblay E, Chambers AF. Osteopontin-induced, integrin-dependent migration of human mammary epithelial cells involves activation of the hepatocyte growth factor receptor (Met). J Cell Biochem. 2000; 78:465-475.

61. Mitra AK, Sawada K, Tiwari P, Mui K, Gwin K, Lengyel E. Ligand-independent activation of c-Met by fibronectin and alpha(5)beta(1)-integrin regulates ovarian cancer invasion and metastasis. Oncogene. 2011; 30:1566-1576.
62. Rong S, Segal S, Anver M, Resau JH, Vande Woude GF. Invasiveness and metastasis of NIH 3 T3 cells induced by Met-hepatocyte growth factor/scatter factor autocrine stimulation. Proceedings of the National Academy of Sciences of the United States of America. 1994; 91:4731-4735.

63. Birchmeier C, Birchmeier W, Gherardi E, Vande Woude GF. Met, metastasis, motility and more. Nature reviews Molecular cell biology. 2003; 4:915-925.

64. Gentile A, Comoglio PM. Invasive growth: a genetic program. Int J Dev Biol. 2004; 48:451-456.

65. Miyauchi A, Alvarez J, Greenfield EM, Teti A, Grano M, Colucci S, Zambonin-Zallone A, Ross FP, Teitelbaum SL, Cheresh D, et al. Recognition of osteopontin and related peptides by an alpha v beta 3 integrin stimulates immediate cell signals in osteoclasts. J Biol Chem. 1991; 266:20369-20374.

66. Kang Y, Siegel PM, Shu W, Drobnjak M, Kakonen SM, Cordon-Cardo C, Guise TA, Massague J. A multigenic program mediating breast cancer metastasis to bone. Cancer Cell. 2003; 3:537-549.

67. McAllister SS, Gifford AM, Greiner AL, Kelleher SP, Saelzler MP, Ince TA, Reinhardt F, Harris LN, Hylander BL, Repasky EA, Weinberg RA. Systemic endocrine instigation of indolent tumor growth requires osteopontin. Cell. 2008; 133:994-1005.

68. Cao L, Fan X, Jing W, Liang Y, Chen R, Liu Y, Zhu M, Jia R, Wang H, Zhang X, Zhang Y, Zhou X, Zhao J, Guo Y. Osteopontin promotes a cancer stem cell-like phenotype in hepatocellular carcinoma cells via an integrin-NF-kappaBHIF-1 alpha pathway. Oncotarget. 2015; 6:6627-6640.

69. Coppola D, Szabo M, Boulware D, Muraca P, Alsarraj M, Chambers AF, Yeatman TJ. Correlation of osteopontin protein expression and pathological stage across a wide variety of tumor histologies. Clin Cancer Res. 2004; 10:184-190.

70. Oldberg A, Franzen A, Heinegard D. Cloning and sequence analysis of rat bone sialoprotein (osteopontin) cDNA reveals an Arg-Gly-Asp cell-binding sequence. Proc Natl Acad Sci U S A. 1986; 83:8819-8823.

71. El-Tanani MK. Role of osteopontin in cellular signaling and metastatic phenotype. Front Biosci. 2008; 13:4276-4284.

72. Anborgh PH, Mutrie JC, Tuck AB, Chambers AF. Role of the metastasis-promoting protein osteopontin in the tumour microenvironment. J Cell Mol Med. 2010; 14:2037-2044.

73. Weber GF. The cancer biomarker osteopontin: combination with other markers. Cancer Genomics Proteomics. 2011; 8:263-288.

74. Senger DR, Wirth DF, Hynes RO. Transformed mammalian cells secrete specific proteins and phosphoproteins. Cell. 1979; 16:885-893.

75. Chackalaparampil I, Peri A, Nemir M, McKee MD, Lin PH, Mukherjee BB, Mukherjee AB. Cells in vivo and in vitro from osteopetrotic mice homozygous for c-src disruption show 
suppression of synthesis of osteopontin, a multifunctional extracellular matrix protein. Oncogene. 1996; 12:1457-1467.

76. Sharma P, Kumar S, Kundu GC. Transcriptional regulation of human osteopontin promoter by histone deacetylase inhibitor, trichostatin A in cervical cancer cells. Mol Cancer. 2010; 9:178.

77. Arnsdorf EJ, Tummala P, Castillo AB, Zhang F, Jacobs CR. The epigenetic mechanism of mechanically induced osteogenic differentiation. J Biomech. 2010; 43:2881-2886.

78. Tezuka K, Denhardt DT, Rodan GA, Harada S. Stimulation of mouse osteopontin promoter by $\mathrm{v}$-Src is mediated by a CCAAT box-binding factor. J Biol Chem. 1996; 271:22713-22717.

79. Wang X, Louden C, Ohlstein EH, Stadel JM, Gu JL, Yue TL. Osteopontin expression in platelet-derived growth factor-stimulated vascular smooth muscle cells and carotid artery after balloon angioplasty. Arterioscler Thromb Vasc Biol. 1996; 16:1365-1372.

80. Whalen KA, Weber GF, Benjamin TL, Schaffhausen BS. Polyomavirus middle $\mathrm{T}$ antigen induces the transcription of osteopontin, a gene important for the migration of transformed cells. J Virol. 2008; 82:4946-4954.

81. Oates AJ, Barraclough R, Rudland PS. The role of osteopontin in tumorigenesis and metastasis. Invasion Metastasis. 1997; 17:1-15.

82. Weber GF, Cantor H. The immunology of Eta-1/osteopontin. Cytokine Growth Factor Rev. 1996; 7:241-248.

83. Rittling SR, Chambers AF. Role of osteopontin in tumour progression. Br J Cancer. 2004; 90:1877-1881.

84. Denhardt DT, Noda M, O'Regan AW, Pavlin D, Berman JS. Osteopontin as a means to cope with environmental insults: regulation of inflammation, tissue remodeling, and cell survival. J Clin Invest. 2001; 107:1055-1061.

85. Scatena M, Liaw L, Giachelli CM. Osteopontin: a multifunctional molecule regulating chronic inflammation and vascular disease. Arterioscler Thromb Vasc Biol. 2007; 27:2302-2309.

86. Senger DR, Perruzzi CA, Papadopoulos A, Tenen DG. Purification of a human milk protein closely similar to tumor-secreted phosphoproteins and osteopontin. Biochim Biophys Acta. 1989; 996:43-48.

87. Christensen B, Schack L, Klaning E, Sorensen ES. Osteopontin is cleaved at multiple sites close to its integrinbinding motifs in milk and is a novel substrate for plasmin and cathepsin D. J Biol Chem. 2010; 285:7929-7937.

88. Courter D, Cao H, Kwok S, Kong C, Banh A, Kuo P, Bouley DM, Vice C, Brustugun OT, Denko NC, Koong AC, Giaccia A, Le QT. The RGD domain of human osteopontin promotes tumor growth and metastasis through activation of survival pathways. PLoS One. 2010; 5:e9633.
89. Chae S, Jun HO, Lee EG, Yang SJ, Lee DC, Jung JK, Park KC, Yeom YI, Kim KW. Osteopontin splice variants differentially modulate the migratory activity of hepatocellular carcinoma cell lines. Int J Oncol. 2009; 35:1409-1416.

90. Tilli TM, Franco VF, Robbs BK, Wanderley JL, da Silva FR, de Mello KD, Viola JP, Weber GF, Gimba ER. Osteopontin-c splicing isoform contributes to ovarian cancer progression. Mol Cancer Res. 2011; 9:280-293.

91. Vleminckx K, Vakaet L Jr, Mareel M, Fiers W, van Roy F. Genetic manipulation of E-cadherin expression by epithelial tumor cells reveals an invasion suppressor role. Cell. 1991; 66:107-119.

92. Saha B, Chaiwun B, Imam SS, Tsao-Wei DD, Groshen S, Naritoku WY, Imam SA. Overexpression of E-cadherin protein in metastatic breast cancer cells in bone. Anticancer Res. 2007; 27:3903-3908.

93. Saha B, Arase A, Imam SS, Tsao-Wei D, Naritoku WY, Groshen S, Jones LW, Imam SA. Overexpression of E-cadherin and beta-catenin proteins in metastatic prostate cancer cells in bone. Prostate. 2008; 68:78-84.

94. Putzke AP, Ventura AP, Bailey AM, Akture C, OpokuAnsah J, Celiktas M, Hwang MS, Darling DS, Coleman IM, Nelson PS, Nguyen HM, Corey E, Tewari M, Morrissey C, Vessella RL, Knudsen BS. Metastatic progression of prostate cancer and e-cadherin regulation by zeb1 and SRC family kinases. Am J Pathol. 2011; 179:400-410.

95. Armstrong AJ, Marengo MS, Oltean S, Kemeny G, Bitting RL, Turnbull JD, Herold CI, Marcom PK, George DJ, Garcia-Blanco MA. Circulating tumor cells from patients with advanced prostate and breast cancer display both epithelial and mesenchymal markers. Mol Cancer Res. 2011; 9:997-1007.

96. Blin N, Stafford DW. A general method for isolation of high molecular weight DNA from eukaryotes. Nucleic Acids Res. 1976; 3:2303-2308.

97. Giordano TJ, Shedden KA, Schwartz DR, Kuick R, Taylor JM, Lee N, Misek DE, Greenson JK, Kardia SL, Beer DG, Rennert G, Cho KR, Gruber SB, Fearon ER, Hanash S. Organ-specific molecular classification of primary lung, colon, and ovarian adenocarcinomas using gene expression profiles. Am J Pathol. 2001; 159:1231-1238.

98. Lin J, Lin L, Thomas DG, Greenson JK, Giordano TJ, Robinson GS, Barve RA, Weishaar FA, Taylor JM, Orringer MB, Beer DG. Melanoma-associated antigens in esophageal adenocarcinoma: identification of novel MAGE-A10 splice variants. Clin Cancer Res. 2004; 10:5708-5716.

99. Livak KJ, Schmittgen TD. Analysis of relative gene expression data using real-time quantitative PCR and the 2(-Delta Delta C(T)) Method. Methods. 2001; 25:402-408. 
100. Lin L, Bass AJ, Lockwood WW, Wang Z, Silvers AL, Thomas DG, Chang AC, Lin J, Orringer MB, Li W, Glover TW, Giordano TJ, Lam WL, Meyerson M, Beer DG. Activation of GATA binding protein 6 (GATA6) sustains oncogenic lineage-survival in esophageal adenocarcinoma. Proc Natl Acad Sci U S A. 2012; 109:4251-4256.

101. Lin L, Aggarwal S, Glover TW, Orringer MB, Hanash S, Beer DG. A minimal critical region of the 8p22-23 amplicon in esophageal adenocarcinomas defined using sequence tagged site-amplification mapping and quantitative polymerase chain reaction includes the GATA-4 gene. Cancer Res. 2000; 60:1341-1347.
102. Kononen J, Bubendorf L, Kallioniemi A, Barlund M, Schraml P, Leighton S, Torhorst J, Mihatsch MJ, Sauter G, Kallioniemi OP. Tissue microarrays for high-throughput molecular profiling of tumor specimens. Nat Med. 1998; 4:844-847.

103. Lin J, Raoof DA, Wang Z, Lin MY, Thomas DG, Greenson JK, Giordano TJ, Orringer MB, Chang AC, Beer DG, Lin L. Expression and effect of inhibition of the ubiquitin-conjugating enzyme E2C on esophageal adenocarcinoma. Neoplasia. 2006; 8:1062-1071. 